\title{
BGU 4, 1132 y el uso judío de la ley helenística. Texto griego, traducción e interpretación
}

\author{
BGU 4, 1132 and the Jewish use of Hellenistic law. Greek text, \\ translation and interpretation
}

\author{
Paola Druille \\ paodruille@gmail.com \\ Universidad Nacional de La Pampa. Instituto \\ Interdisciplinario de Estudios Americanos y \\ Europeos (IDEAE, FCH, UNLPam) - CONICET, \\ Argentina
}

Recepción: 03 Marzo 2020

Aprobación: 16 Junio 2020

Publicación: 22 Septiembre 2021

Cita sugerida: Druille, P. (2021). BGU 4, 1132 y el uso judío de la ley helenística. Texto griego, traducción e interpretación. Sociedades Precapitalistas, 11, e065. https://doi.org/10.24215/22505121e065
Resumen: El objetivo de este trabajo es, en primer lugar, presentar la primera traducción del griego al castellano del papiro BGU 4, 1132, con notas que recuperan las restauraciones léxicas de los distintos editores. Esta traducción, y su correspondiente anotación, es una novedad entre los estudios modernos en lengua castellana relacionados con BGU 4,1132. En segundo lugar, analizar el uso judío de la ley helenística vigente en Alejandría durante los primeros años del Imperio romano a través de la

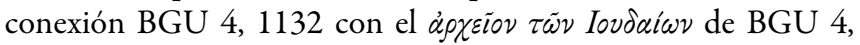

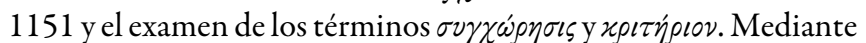
la traducción al castellano de BGU 4, 1132, su contextualización histórico-social y su comunicación con BGU 4, 1151, también discutiremos sobre la posible identidad judía de los nombres propios del papiro, y sobre los términos técnicos que informan sobre los judíos y la ley helenística del siglo I a.C.

Palabras clave: BGU 4, 1132, Traducción, Judíos, Ley helenística, Interpretación.

Abstract: The aim of this work is, first, to present the first translation from Greek to Spanish of the papyrus BGU 4, 1132, with notes that recover the lexical restorations of the different editors. This translation, and its corresponding annotation, is a novelty among modern studies in Spanish related to BGU 4, 1132. Second, to analyze the Jewish use of the Hellenistic law active in Alexandria during the first years of the Roman Empire through the connection BGU 4, 1132 with the apxeĩov $\tau \tilde{\omega} \nu$ Iov $\alpha$ i $\omega \nu$ of BGU 4, 1151 and the examination of the terms

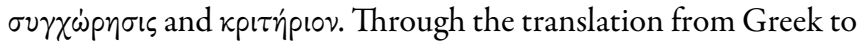
Spanish of BGU 4, 1132, its historical-social contextualization, and its communication with BGU 4, 1151, we will also discuss the possible Jewish identity of the papyrus proper names, and the technical terms that inform about the Jews and the Hellenistic law of the 1 st century B.C.

Keywords: BGU 4, 1132, Translation, Jews, Hellenistic , Hellenistic law, Interpretation. 


\section{Introducción}

BGU 4,1132 es un papiro egipcio datado el día 24 de junio del año 14/13 a.C., que integra un grupo de ocho documentos posiblemente judíos descubiertos como cartonaje de las momias de la necrópolis de Abu Sir al-Malaq en 1902-1905, ${ }^{1}$ procedentes del archivo notarial de Alejandría ${ }^{2}$ y redactados en

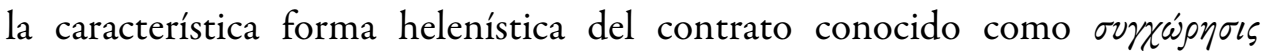
(Yiftach y Vandorpe, 2019, p. 182). ${ }^{3}$

Fue publicado por primera vez en el volumen IV de Berliner Griechische Urkunden con el número 1132 (1912, pp. 240-242), a partir de la restauración y edición crítica realizada por Schubart. Gracias a su trabajo se pudo conocer que la parte final del documento se ha perdido, mientras que la parte inicial permanece en muy buen estado de conservación, a excepción de algunas lagunas esporádicas que Schubart enmienda y reconstruye con éxito. Este inicio contiene una $\sigma v \gamma \chi \omega ́ \rho \eta \sigma \iota \zeta$ estructurada en una columna de 38 líneas, que registra cuatro $\sigma \nu \gamma \chi \omega \rho \dot{\sigma} \sigma \varepsilon ı \zeta$ más relativas a transacciones de préstamos vinculadas con dinero y tierras de la chóra de Alejandría. Sobre esta base, el editor reconstruye el contenido del papiro, que interpreta como el historial jurídico de un acuerdo contraído entre Ammonio, Teodoro y Alejandro, destinado a evitar un pleito o concluir un litigio. De esto deduce que BGU 4, 1132 es una sentencia judicial, y que son las mismas partes de la relación en disputa las que ponen fin a la controversia, con los mismos efectos que la decisión del magistrado jurídico que recibe el contrato. El editor también consigue establecer una indicación precisa

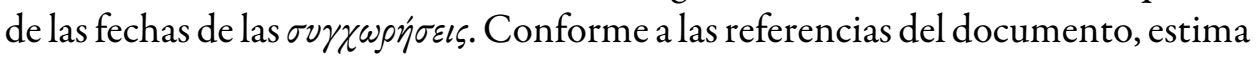

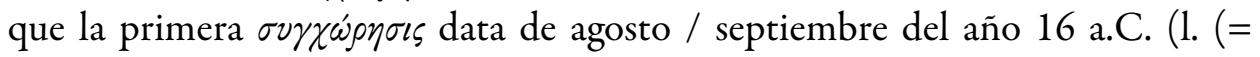
línea) 6), la segunda de septiembre / octubre del año 16 a.C. (1. 25), la tercera de octubre / noviembre del año 15 a.C. (1. 31), y la cuarta de mayo / junio del año 14/13 a.C. (1. 38). Esta última referencia es utilizada por Schubart para la datación definitiva del papiro.

Más tarde, Tcherikover y Fuks reeditan el trabajo de Schubart, con pequeños agregados a la restauración original, e incluyen el documento con el número 142 en "Jews in Alexandria in the Early Roman Period" (sección VII) del volumen II del Corpus Papyrorum Judaicarum (1960, pp. 5-8), acompañado con una traducción al inglés del mismo (pp. 7-8). Mediante la inserción arbitraria de palabras que la reconstrucción de Schubart ni siquiera insinúa, intentan

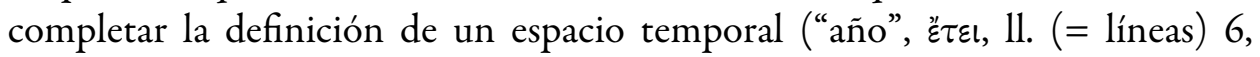

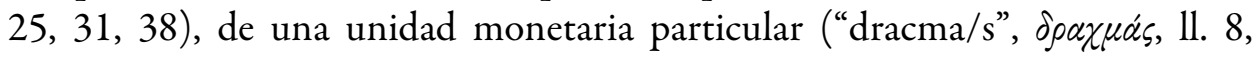
$28,34,35 ; \delta \rho \alpha \chi \mu \tilde{\omega} \nu, 11.21,26,27)$, o de la fracción de una parcela de tierra ("mitad", $\eta \mu \iota \sigma \nu, 1.13$ ). Tcherikover y Fuks, sin embargo, no reparan las lagunas del papiro dejadas sin enmienda por Schubart, ni suman nueva información fuera de la consignada en las palabras añadidas. Solo proponen una interpretación del documento (pp. 5-6) que difiere en gran medida de la planteada por Schubart. Basados en los datos registrados, los editores no consideran el texto como una sentencia judicial; asumen que el papiro contiene un acuerdo sobre una deuda vencida que Alejandro debe al prestamista Ammonio, junto con las cláusulas para convenir el pago correspondiente. La deuda fue contraída por Teodoro,

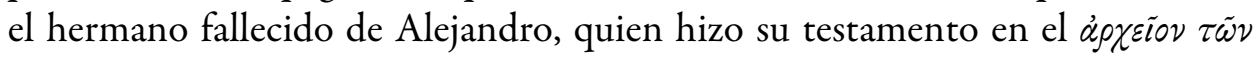
Iovdai $\omega \nu$, según explican los editores luego de la puesta en comunicación de BGU 
4, 1132 con otro papiro del mismo grupo alejandrino, catalogado como BGU 4, 1151. Con la ayuda de esta conexión, Tcherikover y Fuks concluyen que ambos hermanos son judíos (p. 5), sin aportar otros datos que confirmen este supuesto. En relación con el contenido del documento, analizan la parte preservada como

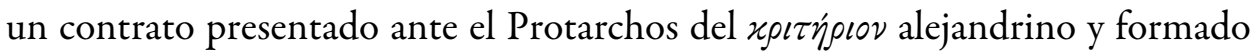
por cuatro $\sigma \nu \gamma \chi \omega \rho \eta ́ \sigma \varepsilon \iota \varsigma$ anteriores a la final, cuyo texto completo no se conserva.

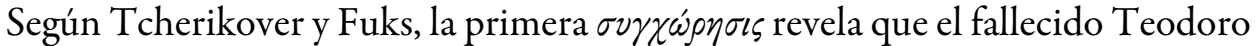
había tomado prestado de Ammonio una suma de 500 dracmas. Cuando no pudo pagar su deuda, algunas parcelas de su tierra en la chóra de Alejandría fueron subastadas y derribadas por una prosbolé a favor del acreedor. En consecuencia, la deuda se redujo en 200 dracmas. Las siguientes tres $\sigma v \gamma \chi \omega \rho \eta \dot{\sigma \varepsilon \iota \varsigma}$ tratan sobre préstamos adicionales de 500, 200 y 200 dracmas respectivamente. Los editores

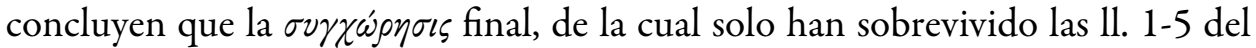
documento, podría haber referido al pago de la deuda por parte de Alejandro, o al compromiso de saldar la deuda de su hermano Teodoro. ${ }^{4}$

Pese a las diferentes interpretaciones del texto del papiro, las ediciones de Schubart y Tcherikover y Fuks son de suma importancia para conocer los detalles de un documento jurídico de gran relevancia histórica. Luego del examen crítico de los elementos gráficos de la escritura del texto conservado, los editores coinciden en localizar el papiro en Alejandría y datar su aparición en los primeros años del Imperio romano, aunque Schubart no arriesga ninguna consideración sobre la identidad judía de las partes involucradas en el contrato. Esta tesis propuesta por Tcherikover y Fuks, sin embargo, fue aceptada por los investigadores modernos (Gambetti, 2009, p. 52, nota 115) que no encuentran razones para refutar la conclusión de los editores. Tampoco fue rechazada la tesis sobre la influencia de la ley helenística en los asuntos de los judíos de Alejandría propuesta por los mismos editores (I, 1957, pp. 32-34), y por los estudiosos Goodenough (1929), Mélèze Modrzejewski (1961, pp. 162-177; 1996), Kasher (1985) y Schwartz (2017), como lo demuestra BGU 4, 1132.

En este sentido, dividiremos nuestro estudio en las siguientes partes. En primer lugar, presentaremos la primera traducción del griego al castellano de BGU 4, 1132, con notas que recuperan las restauraciones léxicas de los distintos editores. Esta traducción, y su correspondiente anotación, es una novedad entre los estudios modernos en lengua castellana relacionados con BGU 4,1132. En segundo lugar, analizaremos el uso judío de la ley helenística vigente en Alejandría durante los primeros años del Imperio romano a través de la conexión

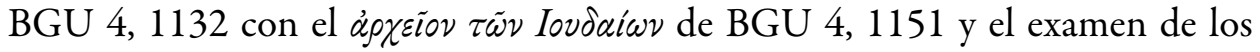

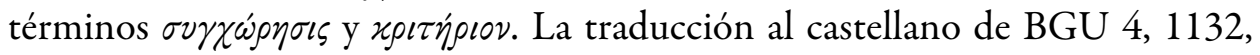
su contextualización histórica y social y su comunicación con BGU 4, 1151 y otras fuentes contemporáneas a las referencias léxicas que registra, también nos permitirá discutir sobre la posible identidad judía de los nombres anotados en el papiro, y sobre el entramado de términos técnicos que proporcionan información relacionada con los judíos y la ley helenística del siglo I a.C.

\section{Texto griego, traducción y estructura de BGU 4, 1132}

La traducción de BGU 4, 1132 que presentamos a continuación mantiene la disposición del texto griego editado por Schubart (1912) y Tcherikover y 
Fuks (1960). ${ }^{5}$ Sus ediciones están determinadas por la parte inicial del documento, cuyo desarrollo completo está perdido. Esta mutilación y el estado fragmentario del texto preservado no parecen haber oscurecido la comprensión de la temática completa del papiro. Las restauraciones de las partes conservadas llevadas a cabo por Schubart y el léxico agregado por Tcherikover y Fuks aportan datos referenciales que pueden ser descifrados y contextualizados con cierto grado de satisfacción:

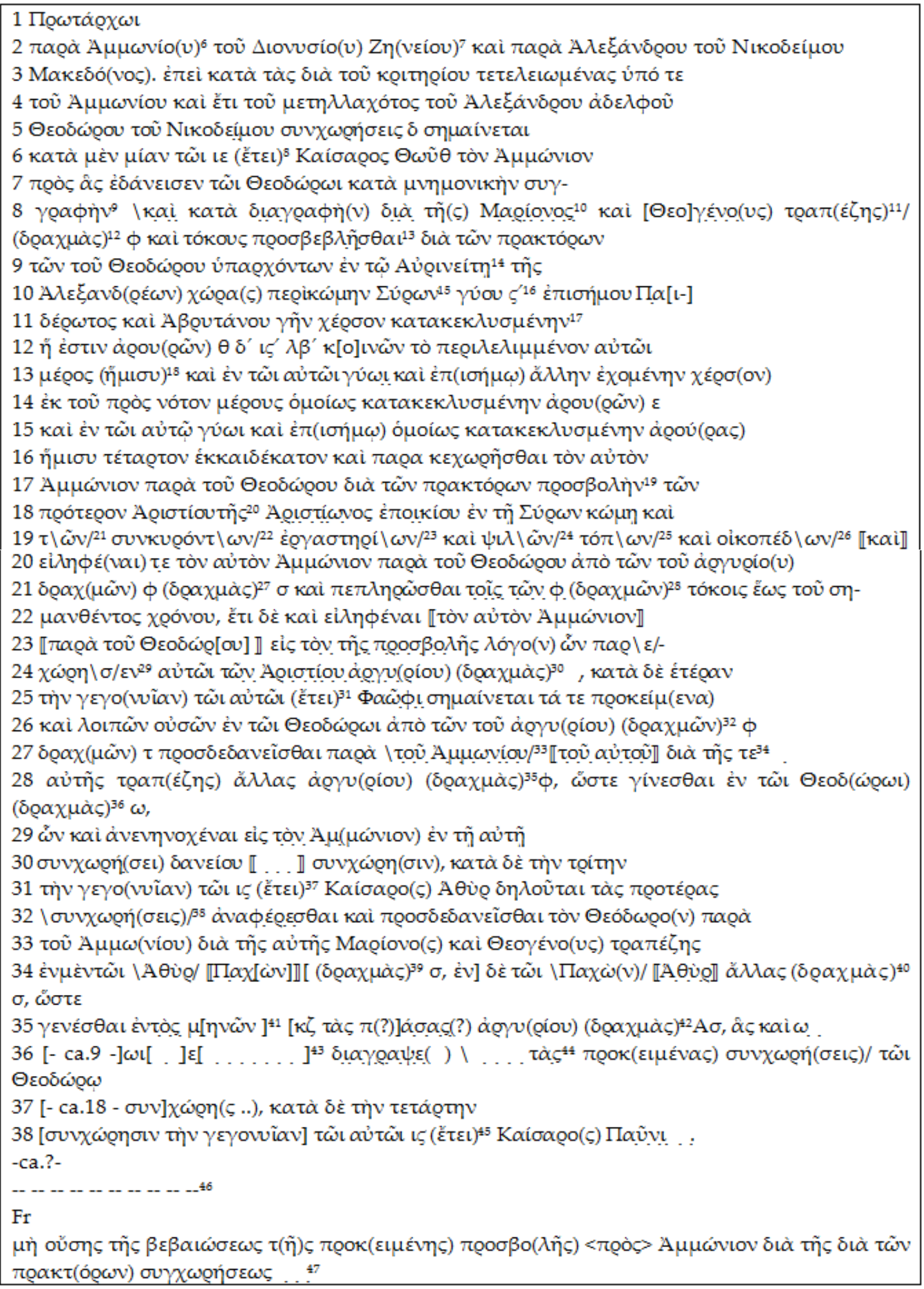




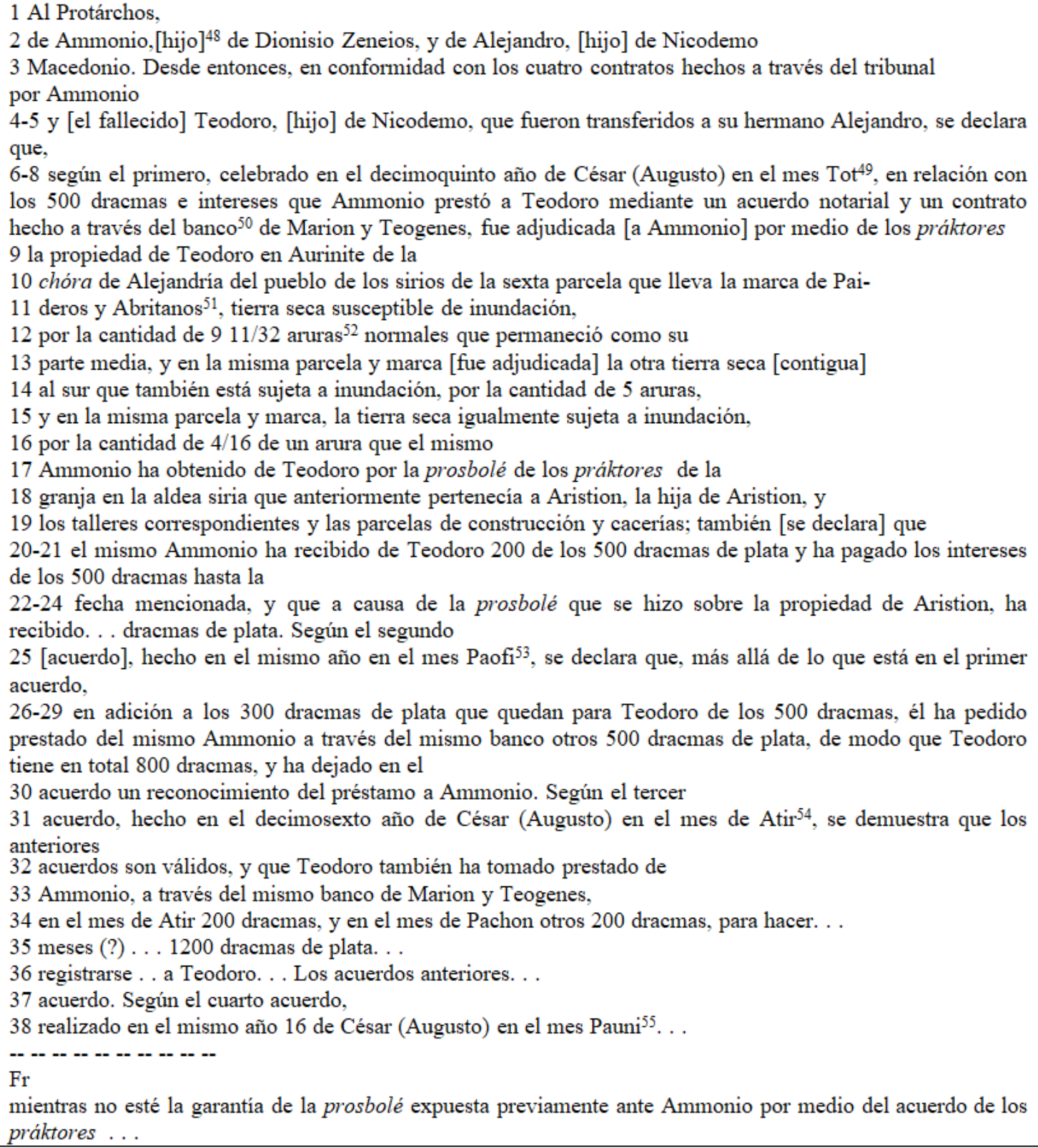

Como se observa en nuestra traducción, el texto permite identificar tres partes bien definidas:

a. (11. 1-5) Los nombres de los involucrados en el documento, entre los que surgen la autoridad judicial conocida como Protárchos (1. 1) y Ammonio, Alejandro y su fallecido hermano Teodoro (11. 2-5), que son las partes privadas del contrato. También se registra el nombre del órgano judicial que intervino en los acuerdos, el

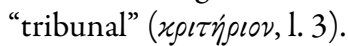

(11. 6-38) Las cuatro $\sigma \gamma \chi \chi \omega \rho \dot{\sigma \varepsilon ı \varsigma \varsigma ~ c o n t r a i ́ d a s ~ e n t r e ~ A m m o n i o, ~ T e o d o r o ~ y ~ A l e j a n d r o . ~}$ La primera es anterior a la redacción de BGU 4, 1132, y refiere a un préstamo otorgado por Ammonio a Teodoro y los intereses correspondientes, el incumplimiento del acuerdo establecido y la incautación de la propiedad inmueble de Teodoro por acción de los práktores y de la prosbolé (11. 6-24). La segunda declara otro préstamo hecho por Ammonio a Teodoro (11. 24-30). La tercera valida los acuerdos anteriores, al mismo tiempo que registra un nuevo préstamo del mismo 


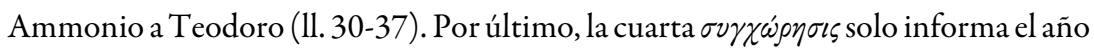
de emisión (11. 37-38); el resto se ha perdido.

b. (Fr.) El pedido de una garantía que otorgue seguridad a Ammonio ante un contrato acordado.

Desafortunadamente no se puede presentar una estructura con el contenido completo del papiro, no por nuestra arbitraria preferencia, sino porque el estado incompleto del texto requiere una gran contextualización que es imposible exponer aquí en su totalidad. Solo se pueden extraer algunos datos referenciales que permitan lograr una aproximación al tema referido por el texto. Estos datos y el vocabulario específico expuesto en cada línea del papiro han dado lugar a distintas interpretaciones que se focalizan fundamentalmente en la identidad de las partes del contrato a partir de la conexión de BGU 4, 1132 con el $\dot{\alpha} \rho x \varepsilon i \tilde{o} \nu \tau \tilde{\omega} \nu$

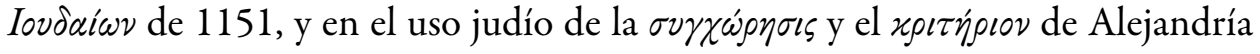
romana.

\section{a. El archeîon tôn Ioudaion}

El papiro BGU 4, 1132 menciona distintos nombres propios involucrados en un contrato por un préstamo monetario. Uno es "Ammonio, [hijo] de Dionisio Zeneios" (1. 2), y los otros son "Alejandro, [hijo] de Nicodemo Macedonio" 56 (11. 2-5a), y su hermano, "[el fallecido] Teodoro" (11. 4-5a). El mismo documento nombra a su vez instrumentos legales y órganos jurídicos, como las $\sigma v \gamma \chi \omega \rho \eta ́ \sigma \varepsilon ı \varsigma$

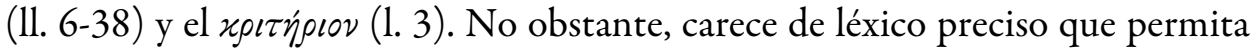
reconocer la identidad judía de las partes responsables del contrato. Sin bien esto se puede deducir mediante un examen onomástico, Ammonio, Alejandro y Teodoro no son nombres usados exclusivamente por judíos. Fueron llevados con frecuencia por judíos y no judíos del período ptolemaico y romano. ${ }^{57}$ Esta identidad tampoco se puede deducir de los documentos y del órgano jurídico anotado en el texto; los mismos fueron típicamente helenísticos, según se analizará más adelante. Semejante ausencia de pruebas impide demostrar la presencia de judíos en el papiro, a excepción de la aparición de Iovdaios en BGU 4, 1151, que es un papiro del grupo de ocho documentos alejandrinos encontrados en la necrópolis de Abu Siral-Malaq y directamente conectado con 1132.

BGU 4,1151 está datado el día 27/25 de abril del año 13 a.C. Contiene un texto formado por 25 líneas en una sola columna que registran un acuerdo compuesto por las siguientes partes: 1) la confirmación de un pago o el recibo por una suma de 200 dracmas legadas a Dionisia por el fallecido Teodoro a través de

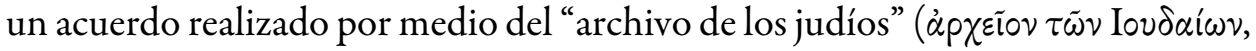
11.2-8); 2) la ratificación de Dionisia de haber recibido 100 dracmas de Alejandro, el hermano de Teodoro (1. 5), y la cláusula para el pago de las 100 dracmas restantes, que establece entregas en cuotas sin interés en el plazo de 17 meses (l. 10); 3) el contrato con las multas en caso de incumplimiento por parte del deudor (11. 13-25). De acuerdo con esta estructura del documento, se observa que en el acuerdo surgen nuevamente los nombres Alejandro y Teodoro vinculados otra

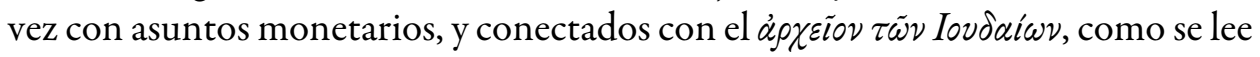
en la sección inicial del papiro que copiamos a continuación: 


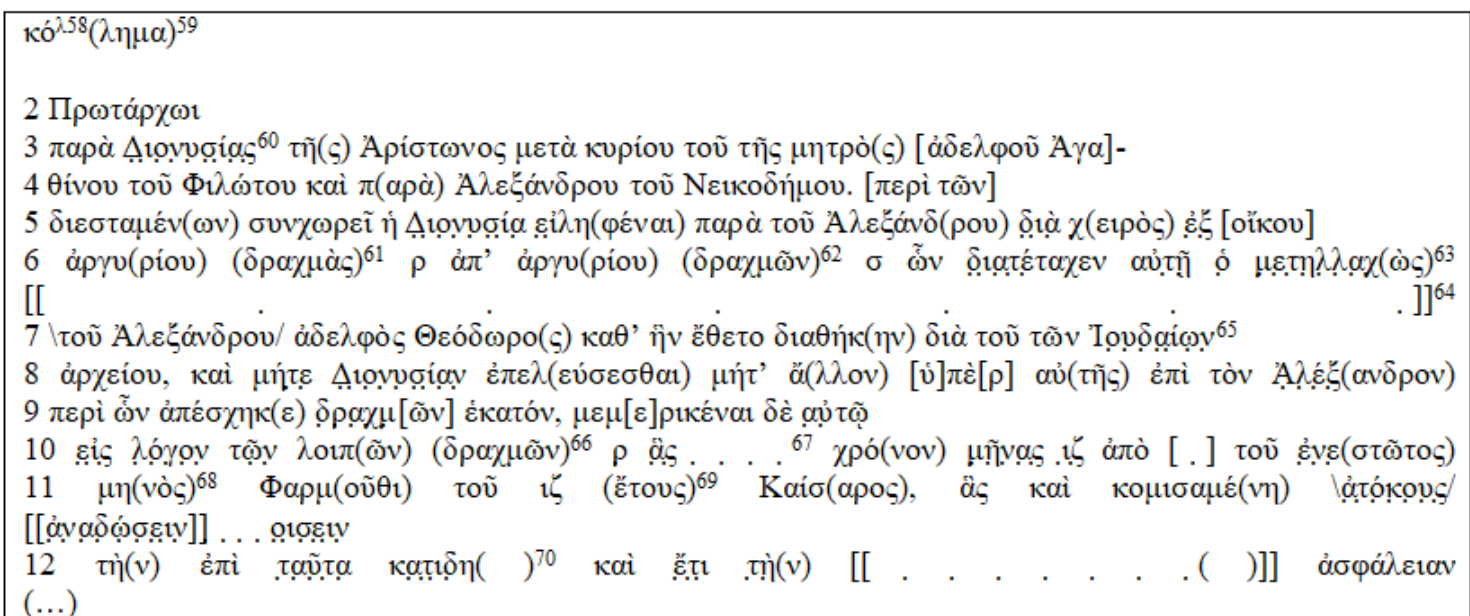

\section{Columna}

\section{A Protárchos,}

3 de Dionisia, la hija de Aríston con su tutor, el hermano de su madre, Agatino,

4 hijo de Filota y de Alejandro, hijo de Nicodemo. Con respecto al

5 asunto en disputa, Dionisia reconoce que recibió debidamente de Alejandro 100

6 de los 200 dracmas de plata que le fueron legados por el difunto hermano

7 de Alejandro, Teodoro, en conformidad con el testamento que fue presentado por medio del archivo de

8 los judíos, y que ni ella ni nadie que actúe por ella procederán contra Alejandro

9 por los 100 dracmas que ha retenido, y que se le ha otorgado

10 para dar cuenta de los 100 dracmas que debe (?) 17 meses a partir del presente

11-12 mes Farmuti ${ }^{71}$ del año 17 de César (Augusto), y que ella los recibirá sin interés. . . seguridad (...)

Las 1l. 2-12 de BGU 4, 1151 se encuentran prácticamente completas, con algunas lagunas reconstruidas exitosamente por Schubart (1912, pp. 276-277). El fragmento revela los datos que informan sobre el legado del fallecido Teodoro a Dionisia, y sobre la declaración de esta voluntad en un testamento no conservado,


un registro público $u$ oficina notarial que tuvo su origen en época ptolemaica (Fraser, 1972, p. 56), cuando cada grupo, tanto los habitantes de las ciudades como la población inscrita en la chóra, tuvo derecho a emplear su propio lenguaje en los acuerdos, redactar contratos ante sus notarios y aplicar sus códigos legales (Taubenschlag, 1955, pp. 607-609). Gracias a este permiso, y como lo prueba

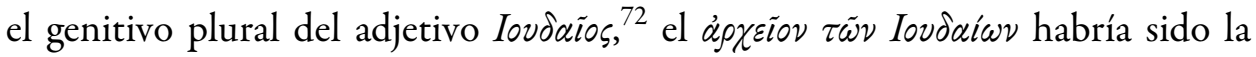
oficina notarial exclusiva de esa comunidad en Alejandría, que se mantuvo en funcionamiento durante la llegada y asentamiento de los romanos. ${ }^{73} \mathrm{BGU}$ 4,1151 no solo menciona la actividad de esta oficina a fines del siglo I a.C., sino que de los ocho documentos del archivo de esa ciudad ${ }^{74}$ es el único papiro que hace referencia a tan importante entidad dependiente posiblemente de la administración de Alejandría. Para Fraser (1972, p. 56), su función habría sido

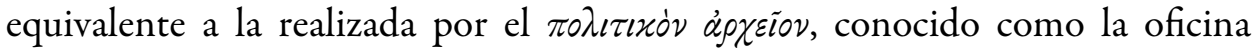
notarial griega de la misma ciudad portuaria, encargada de elaborar y recibir documentos de la población no judía (BGU 4, 1131, 11. 14 y 22). De la misma

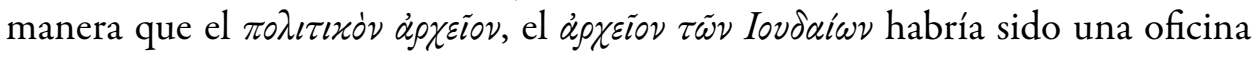
pública de los judíos, regulada por la legislación oficial (Tcherikover y Fuks, II, 1960, p. 4), con autorización para la preparación y aceptación de los documentos privados sobre distintos asuntos de esta comunidad, incluidos los testamentos. 
Así lo demuestra la frase "que le fueron legados por (...) Teodoro, en conformidad con el testamento que fue presentado por medio del archivo de los

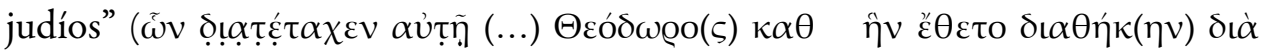



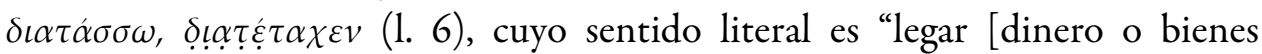
personales] mediante un testamento", es la expresión técnica ${ }^{75}$ que indica la última voluntad de Teodoro declarada en el documento presentado ante el

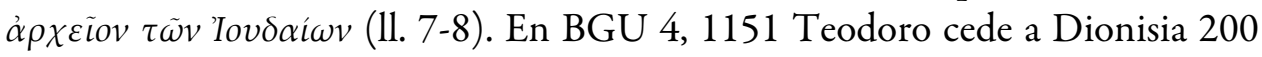
dracmas de su patrimonio y, si bien desconocemos las cláusulas finales, es posible que también haya dispuesto el nombramiento de su hermano Alejandro como tutor y ejecutor del testamento. ${ }^{76}$ Luego de fallecido Teodoro, Alejandro adquiere entonces la obligación contractual de entregar a Dionisia el dinero legado; frente al pago incompleto de las 200 dracmas, Dionisia y Alejandro acuerdan redactar una $\sigma v \gamma \chi \omega ́ \rho \eta \sigma \iota \varsigma$ con cláusulas derivadas del testamento de Teodoro y en consonancia con la legislación helenística, según se advierte en el

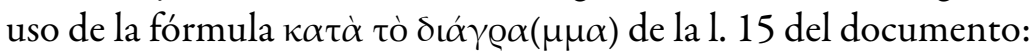

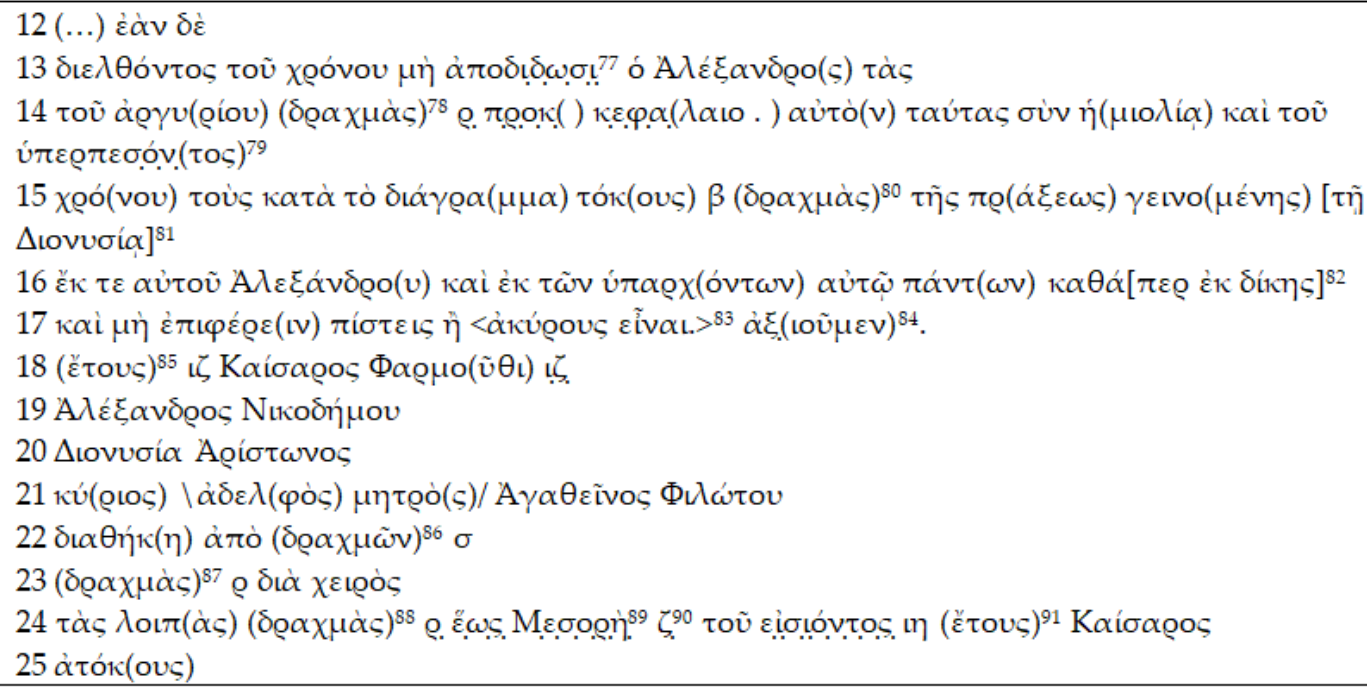

Aquí se detallan las condiciones para el pago de las 100 dracmas que restan del legado de Dionisia, donde se incluyen los intereses moratorios establecidos $\varkappa \alpha \tau \dot{\alpha} \tau \dot{\alpha} \delta \dot{\alpha} \gamma \rho \alpha(\mu \mu \alpha)(1.15) .{ }^{92}$ Esta ley financiera fue posiblemente parte de la legislación ideada por los ptolomeos durante la reorganización jurídica de Egipto 
y adoptada más tarde por los romanos en los primeros años de su Imperio. Si bien los judíos establecidos en $\pi 0 \lambda i \tau \varepsilon v \mu \alpha$ tenían permiso para aplicar sus estatutos

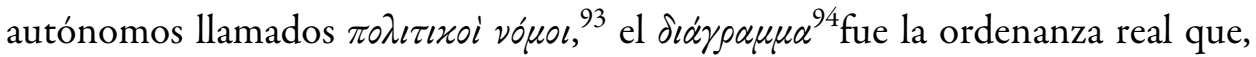
expresada en forma de edicto general (Fraser, 1972, p. 107), superó en autoridad a todas las leyes existentes hasta ese momento (Taubenschlag, 1955, pp. 9-16). Tal ordenanza, que generalmente desarrollaba o aclaraba leyes vigentes, en especial aquellas vinculadas con asuntos fiscales, civiles o económicos ${ }^{95}$ no estimados por

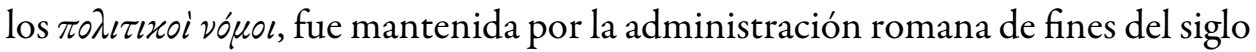
I a.C., principalmente en ciudades como Ptolemais, Naukratis y, especialmente, Alejandría, según se deduce de BGU 4, 1151. La omisión posiblemente regular en los testamentos judíos de una cláusula que estipulara el derecho del heredero a proceder contra el tutor y ejecutor de un testamento en caso de incumplimiento de la voluntad del testador, habría determinado el uso de una disposición que exigiera la entrega del legado fijada en el testamento y gestionara una tasa de interés en beneficio del acreedor, conforme con lo registrado en BGU 4, 1151. Alejandro cuenta con un total de 17 meses para pagar sin interés los 100 dracmas de plata faltantes de la herencia de Dionisia; si incurre en mora, tendrá que pagar otra vez las 200 dracmas más la mitad de este monto y los intereses por el tiempo vencido (11. 13-15), no considerados en el testamento presentado en el $\dot{\rho} \propto \chi \varepsilon \tilde{\imath} 0 \nu \tau \tilde{\omega} \nu$

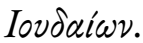

Esta oficina, por lo tanto, otorgaba autenticidad a los documentos en conformidad con las disposiciones legales alejandrinas. Al parecer no se hallaba jerarquizada para fijar tasas de interés por morosidad o falta de pago en casos testamentarios. Su actuación se limitaba a la solicitud de los particulares amparando la exactitud de las cláusulas redactadas en el documento y las declaraciones de voluntad del testador, que quedaban revestidas de la legalidad de su manifestación. Sin embargo, la presencia de esta oficina vinculada con las acciones contractuales de Teodoro y Alejandro, ayuda a deducir la identidad judía de los hermanos de BGU 4, 1132 y, al mismo tiempo, permite conocer la existencia de una entidad judía para los asuntos privados de los integrantes de esa comunidad. Su registro dentro de un documento típicamente helenístico como la

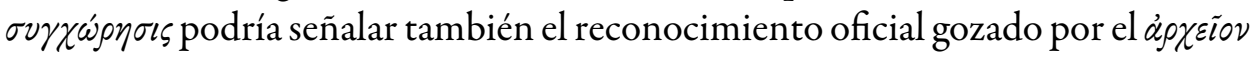

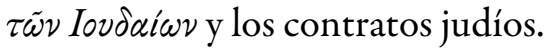

\section{b. La synchóresis}

El papiro BGU 4, 1132 muestra la existencia de cuatro $\sigma \nu \gamma \chi \omega \rho \eta \dot{\sigma \varepsilon ı \varsigma ~ p r e v i a s ~ a ~ l a ~}$

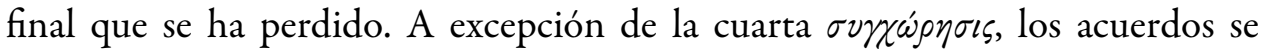
encuentran mencionados en espacios del documento poco deteriorados. $\mathrm{La}$ primera $\sigma v \gamma \chi \omega ́ \rho \eta \sigma \iota \varsigma$ es del año 16 a.C. (11. 6-24) y declara que Ammonio prestó a Teodoro 500 dracmas sujetas a interés. Esta transacción fue realizada "mediante un acuerdo notarial" ( $\alpha \tau \dot{\alpha} \mu \nu \eta \mu \sigma \nu \imath x \dot{\eta} \nu \sigma \nu \gamma \rho \alpha \varphi \dot{\eta} \nu,{ }^{96}$ 1. 7-8) y "un

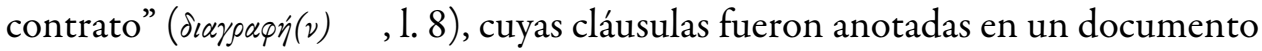
anterior que no se conserva. Sin embargo, BGU 4, 1132 presenta información que señala la falta de devolución de lo convenido, y la actuación de los práktores y la aplicación de la ejecución hipotecaria por "prosbolê" ( $\pi \rho 0 \sigma \beta o \lambda \eta \dot{v}, 1$. 17) para obligar al deudor a cumplir con la responsabilidad acordada. Así el prestador se 
hizo acreedor de distintas parcelas de tierra pertenecientes a Teodoro y ubicadas en la chóra de Alejandría (11. 10-16), incluida una granja en la aldea siria que anteriormente pertenecía a Aristion, con los talleres y las parcelas de

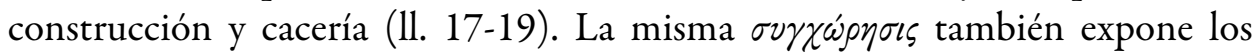
siguientes datos: 1) Ammonio recibió de Teodoro 200 de las 500 dracmas de plata, 2) Teodoro pagó los intereses correspondientes de las 500 dracmas en el tiempo convenido, y 3) Ammonio obtuvo además una suma considerable de dracmas de plata, cuyo monto no es conservado por el documento (11. 20-24). La

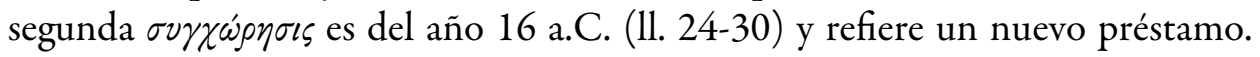
Teodoro pidió a Ammonio 500 dracmas de plata que, junto con las 300 dracmas restantes de las 500 del primer préstamo, sumaron un total de 800 dracmas adeudadas (1l. 25-30). La tercera $\sigma v \gamma \chi \omega ́ \rho \eta \sigma \iota \varsigma$, por su parte, es del año 15 a.C. (1l. 30-37), reafirma la validez de las $\sigma \gamma \gamma \chi \omega \rho \eta ́ \sigma \varepsilon \iota \varsigma$ precedentes (11. 31-37), y declara que Teodoro una vez más tomó prestado de Ammonio otras 400 dracmas en fracciones de 200 cada una (1. 34), elevando su deuda a 1200 dracmas de

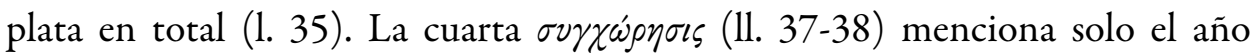
del acuerdo, 14 a.C. (1. 38), que ha servido para la datación de BGU 4, 1132 propuesta por Schubart (1912, p. 240) y Tcherikover y Fuks (II, 1960, p. 5); su contenido no se conserva. Si bien este puede deducirse a partir del fragmento añadido hacia el final de BGU 4, 1132, donde se vuelve a expresar la posible intervención de los prktores y la prosbol correspondiente, no alcanza para realizar una interpretación completa de este acuerdo. Tampoco para determinar

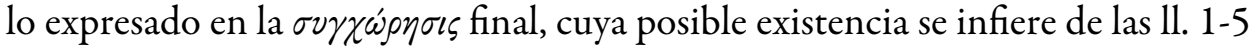
del documento. No obstante, la parte del texto conservado permite entender que

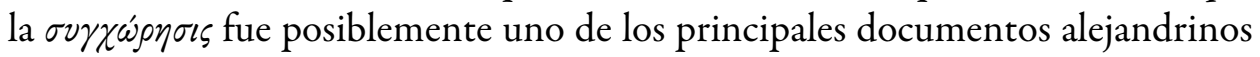
de uso judío para elaborar contratos en el siglo I a.C.

Según Yiftach y Vandorpe (2019, p. 185), a pesar del pequeño número de contratos conocidos, la cantidad de papiros que contienen el documento alejandrino establecido en forma de $\sigma \mho \gamma \chi \omega ́ \rho \eta \sigma \iota \varsigma$ supera de manera considerable a todas las demás formas de contrato (Schubart, 1913, p. 47). La causa de

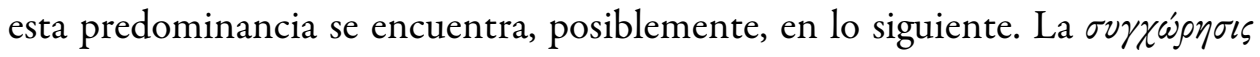
fue un acuerdo privado de carácter no procesal, ${ }^{97}$ desarrollado durante la época ptolemaica como un instrumento de uso voluntario entre dos o más particulares que, de acuerdo con Allam (1984, p. 177), ${ }^{98}$ se habría convertido en un documento específicamente alejandrino durante los primeros años de la conquista romana. En BGU 4, 1132, las cuatro $\sigma v \gamma \chi \omega \rho \eta \dot{\sigma \varepsilon \varepsilon \varsigma}$ fueron presentadas

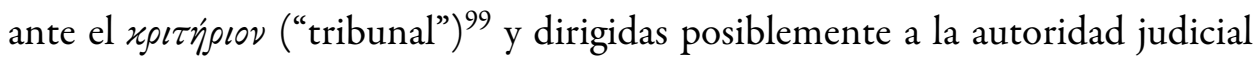
conocida como Protárchos, ${ }^{100}$ que era el jefe del tribunal. ${ }^{101}$ En el caso particular de las $\sigma v \gamma \chi \omega \rho \dot{\sigma} \sigma \varepsilon ı$ de préstamos, es probable que tales documentos tuvieran características propias, como también se deduce de BGU 4, 1132. En primer lugar, este contrato es unilateral; establece obligaciones solo para la parte beneficiaria del préstamo, Teodoro. En segundo lugar es traslativo de dominio. Dado el riesgo que corre Ammonio al prestar el dinero, los cuatro acuerdos protegen su patrimonio con cláusulas que garantizan la recuperación del préstamo e imponen moratorios como rédito para el acreedor. En tercer lugar, la $\sigma v \gamma \chi \omega ́ \rho \eta \sigma \iota s$ es transitiva; los cuatro contratos contraídos por Teodoro "fueron

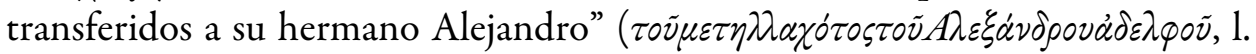
4), quien hereda la deuda de Teodoro junto con la obligación de pagar los nuevos 
intereses productos de la demora en el reembolso del dinero prestado. Estas tres características funcionan como garantía contra el peligro de insolvencia del deudor.

BGU 4, 1132 también menciona una enajenación de bienes que termina

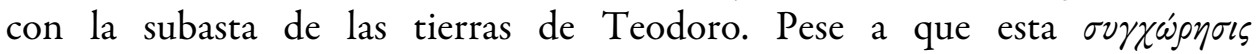
es un documento privado no procesal, es posible suponer que ante la falta de reembolso del préstamo el contrato admitiera una cláusula que permitiera la mediación judicial para el nombramiento de práktores y la prosbolé a favor del prestamista (Wolff, 1941; Rupprecht, 1967, pp. 104-107; Rubinstein, 2010; Yiftach y Vandorpe, 2019, p. 185), según se lee en

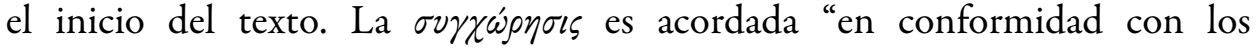
cuatro contratos hechos por Ammonio y [el fallecido] Teodoro a través del tribunal" ( $\alpha \tau \dot{\alpha} \tau \dot{\alpha} \varsigma \delta i \dot{\alpha} \tau 0 \tilde{u} x \rho i \tau \eta \rho i o v \tau \varepsilon \tau \varepsilon \lambda \varepsilon i \omega \mu \varepsilon \dot{v} \alpha s \dot{v} \pi o ́ \tau \varepsilon \tau o \tilde{u} A \mu \mu \omega \nu i o v, 11.3-5)$, que otorga legalidad a la acción contractual, sin emitir una sentencia o resolución final. El término técnico para esto es $\tau \varepsilon \lambda \varepsilon i o ́ \omega$, anotado en el papiro bajo una

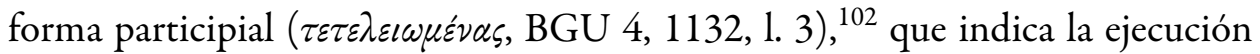
de un instrumento para legalizar los términos acordados, pero no implica un juicio contra el deudor, ni un acto resolutivo como propone Schubart (1912, pp. 240-242). Si bien es probable que BGU 4, 1132 haya concluido con una manifestación de asentimiento de ambas partes, registrada habitualmente con la forma plural del verbo $\dot{\alpha} \xi ı o \omega ~(\dot{\alpha} \xi ı \tilde{\nu} \mu \varepsilon \nu)$ y con el sentido literal de "estamos de acuerdo" presente en otros documentos del grupo alejandrino (BGU 4, 1151, 1.18; 1153 I, l. 10), esto no implica en modo alguno un fallo judicial del tribunal,

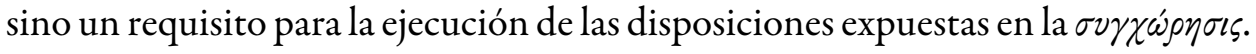

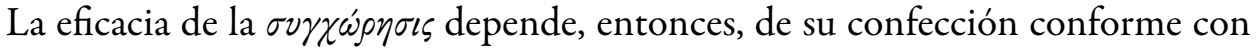

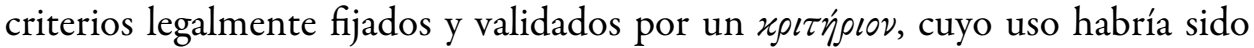
frecuente entre los miembros de la población judía helenizada.

\section{c. El kritérion}

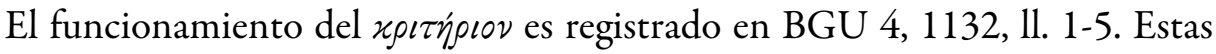
líneas se encuentran en buen estado de conservación y habrían sido parte de una quinta $\sigma v \gamma \chi \omega ́ \rho \eta \sigma \iota \varsigma$ cuyo contenido no ha sobrevivido. Solo se puede conocer que

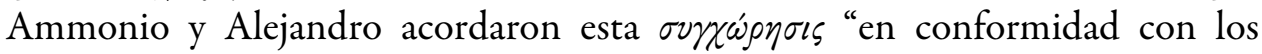
cuatro contratos hechos a través del tribunal por Ammonio y [el fallecido] Teodoro (...) que fueron transferidos a su hermano Alejandro" ( $\varkappa \tau \tau \dot{\alpha} \tau \dot{\alpha} \varsigma \delta i \dot{\alpha} \tau o \tilde{v}$

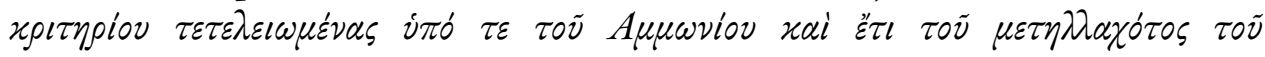

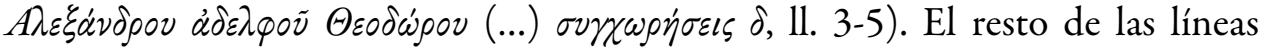
conservadas del documento no vuelve a mencionar este tribunal; tampoco los magistrados que lo integran, a excepción del Protárchos ante quienes Ammonio y Alejandro dirigieron su acuerdo (1. 1). Sin embargo, pese a que BGU 4, 1132 no registra pruebas suficientes sobre la composición y la competencia del

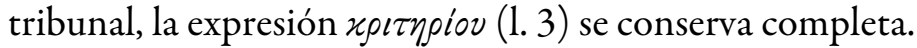

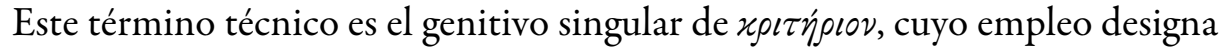
el tribunal de justicia que formó parte del sistema judicial de los ptolomeos,

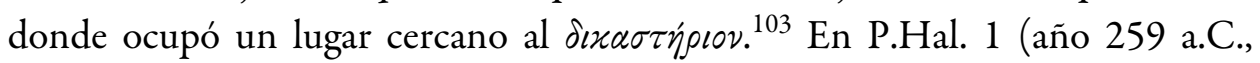
Apolonópolis), los dos tribunales aparecen separados dentro de un documento que contiene una ley con la división de las autoridades judiciales y los tribunales 
de actuación de la corte autónoma de Alejandría ptolemaica (col. II, 1l. 26, 40-44; col. III, 1. 77). ${ }^{104}$ Ambos tribunales surgen nuevamente en el conjunto de decretos del estratega Diofanes (año 218 a.C., Krocodilopolis); aquí se registra

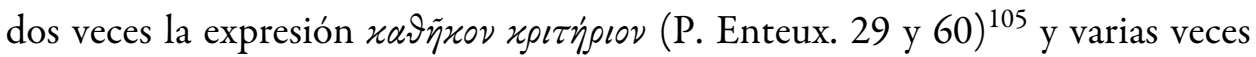

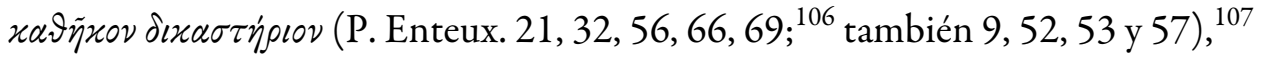
procediendo frente a reclamos de derecho privado. Estos tribunales todavía se mantenían separados hacia fines del siglo III a.C., como lo prueba un extracto de una ordenanza conservada en O.Bodl. I 277 (año 125/101, Tebas), que anota

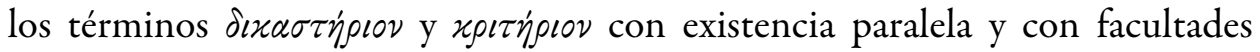
exclusivas (1. 5). Basados en tales evidencias, y frente a la ausencia de fuentes contemporáneas que aludan claramente a las características de cada uno de los órganos, Wolff (1970, p. 97) y Fraser (1972, p. 112) proponen una definición

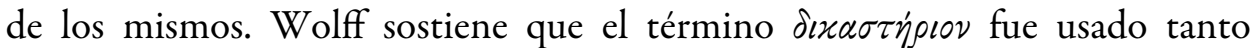
para los tribunales griegos municipales, incluidos los tribunales para extranjeros residentes en Alejandría, como para la propia corte griega de la chóra, llamada Corte de los Diez (P. Gurob 2, et passim). Su definición es compartida por Fraser, quien agrega otros datos. Asegura que el $\delta \varkappa \alpha \sigma \tau \dot{\rho} \rho ı v$ fue una institución propia de la ciudad-Estado, cuyo cuerpo de magistrados fue posiblemente elegido por los ciudadanos. Sin embargo, su importancia disminuyó después del siglo II a.C. Los

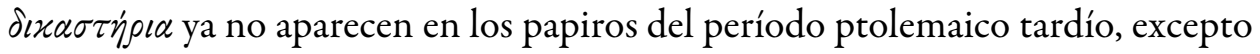
un solo caso registrado en P. Ryl. 2, 68 (11. 8-9, año 89/88 a.C., Hermopolis), que contiene una petición presentada ante el tribunal por un demandante que denuncia los golpes recibidos en la plaza de la ciudad. En relación con el

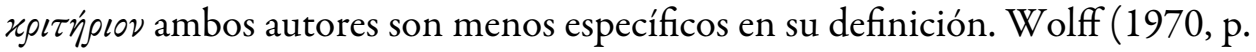

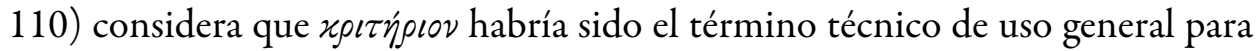
designar cualquier tribunal y, como tal, podría incluir los $\delta \iota x \alpha \sigma \tau \eta_{\rho} \rho \propto$ dentro de su denominación. Fraser (1972, p. 112, también nota 155), por su parte, afirma

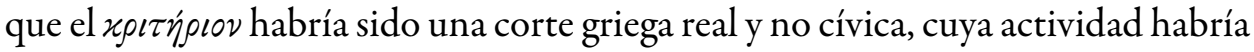
estado concentrada fuera de Alejandría hasta fines del período ptolemaico, ${ }^{108}$

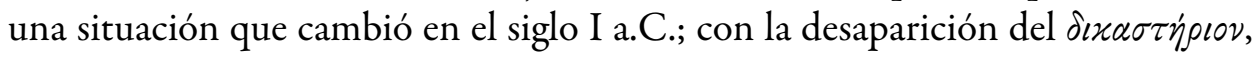

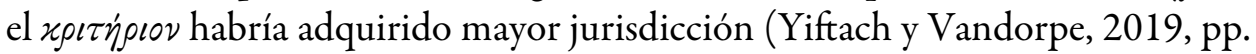
180 y 182), alcanzando casos de los habitantes griegos y extranjeros de esa ciudad y de los territorios bajo su administración. ${ }^{109}$

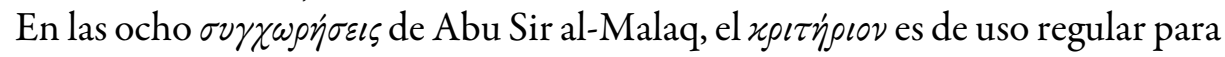
los judíos. ${ }^{110}$ Es nombrado bajo distintas fórmulas de inserción, que oscilan entre

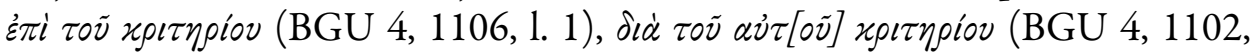

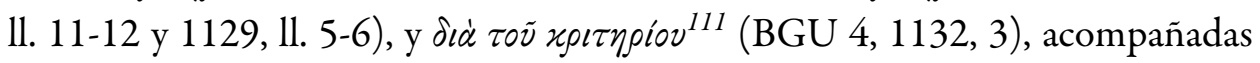
por los términos $\tau \varepsilon \tau \varepsilon \lambda \varepsilon \iota \omega \mu \varepsilon \dot{(}(\nu \eta \nu)$ (BGU 4, 1129, 1. 6) y $\tau \varepsilon \tau \varepsilon \lambda \varepsilon \iota \omega \mu \varepsilon \dot{\varepsilon} \alpha \varsigma$ (BGU $4,1132,1.3)$, indicativos de la validación legal de las $\sigma v \gamma \chi \omega \rho \eta ́ \sigma \varepsilon \iota \varsigma$ presentadas

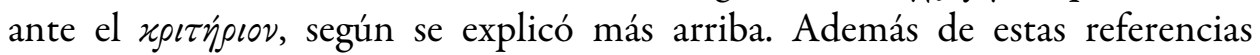
léxicas, la documentación aporta más información posiblemente vinculada con

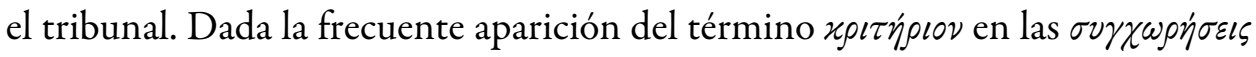
de Abu Sir al-Malaq, y debido a la inexistencia de los $\delta \varkappa \alpha \sigma \tau \eta \dot{\rho} \iota \propto$ en la ciudad

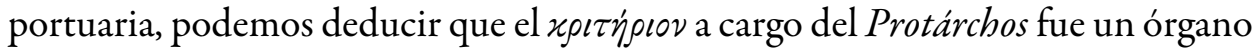
jurisdiccional, probablemente sedentario y permanente, organizado de manera territorial en la ciudad portuaria, donde confluían los acuerdos contraídos por los judíos de la chóra de Alejandría ${ }^{112}$ como lo demuestra BGU 4, 1132. ${ }^{113}$ En 


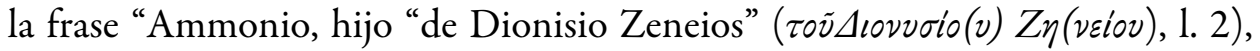

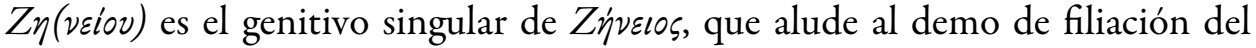
prestador localizado en la chóra de Alejandría (Schubart, 1913, p. 82; Martin, 1932, p. 301; Tcherikover y Fuks, II, 1960, p. 8). Teodoro, por su parte, es propietario de una parcela de tierra ubicada "en Aurinite de la chóra de Alejandría

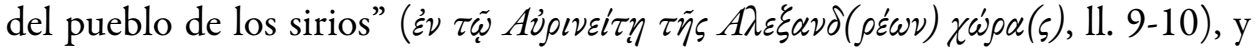
"de los talleres correspondientes y las parcelas de construcción y cacerías" $(\tau \mid \tilde{\omega} \nu /$

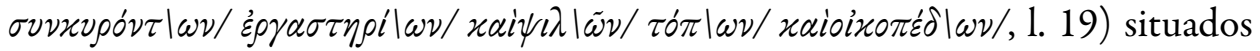
en la misma región. A partir de estos datos se deduce que Zeneios y Aurinite estaban administrados por Alejandría, y los acuerdos jurídicos de los habitantes de tales espacios se encontraban circunscriptos territorialmente a la jurisdicción

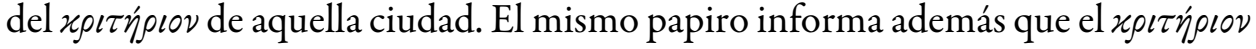
tenía competencia en asuntos de materia privada; fue posiblemente el encargado de garantizar el cumplimiento de las cláusulas del contrato acordado entre Ammonio y Teodoro. De esta manera, cuando el fallecido Teodoro no pudo devolver el dinero prestado por Ammonio (11. 6-8), algunas parcelas de su tierra en Aurinite fueron subastadas y derribadas por prosbole ${ }^{114}$ (11. 17 y 22-24), una vez cumplido el siguiente procedimiento (Taubenschlag, 1955, p. 527).

Si bien desconocemos las distintas instancias atravesadas por Ammonio y Teodoro, la ejecución de una propiedad inmueble ${ }^{115}$ se iniciaba con la denuncia y cálculo administrativo de la deuda, ${ }^{116}$ llevada a cabo por los prktores (11. 6-8 y 17) designados para ejecutar una acción legal de estas características a partir de la identificación de las posesiones del moroso. Concluido este proceso, los bienes de Teodoro fueron retenidos mediante un embargo, puestos en remate y entregados por prosbol a Ammonio. Este procedimiento no es mencionado en BGU 4, 1132. ${ }^{117}$ Solo se refiere que los práktoresdjudicaron la propiedad de Teodoro a Ammonio (11. 5-10), indicando así la reducción de la deuda por incautación. Las otras $\sigma \nu \gamma \chi \omega \rho \eta ́ \sigma \varepsilon ı \zeta$ informan sobre préstamos adicionales de 500, 200 y 200 dracmas respectivamente. La quinta $\sigma v \gamma \chi \omega ́ \rho \eta \sigma \iota \zeta$, finalmente, podría haber expresado el nuevo acuerdo de pago de la deuda por parte de Alejandro, como lo sugieren las $11.2-5$ y el fragmento anexado en la última parte del mismo documento, donde se lee "mientras no esté la garantía de la prosbol expuesta previamente ante Ammonio por medio del acuerdo de



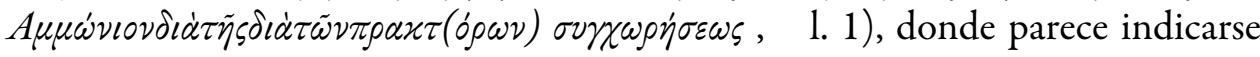
la garantía jurídica pedida por Ammonio a modo de respaldo para contraer un nuevo contrato con el hermano de Teodoro.

No existen otras pruebas que permitan demostrar la acción precisa

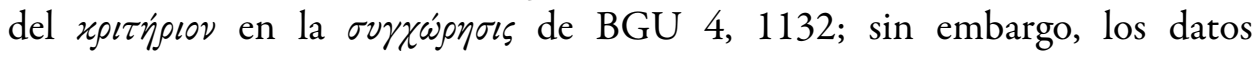

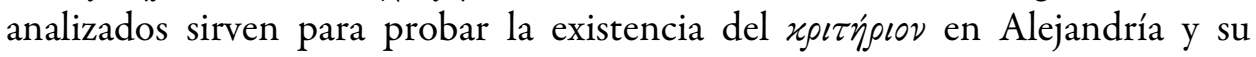
posible competencia jurídica sobre los contratos vinculados con préstamos de particulares judíos. La presencia del Protárchos como jefe del tribunal, de los práktores como los funcionarios encargados de la ejecución de los bienes de Teodoro y de la prosbolé como reconocimiento de la adjudicación de las tierras al acreedor, son referencias que muestran la actuación del tribunal en la subasta por

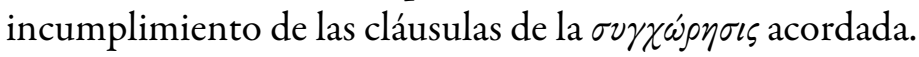




\section{Conclusión}

La traducción del papiro BGU 4, 1132, y su interpretación de los términos técnicos, arroja luz sobre el funcionamiento del sistema jurídico usado por los judíos de Alejandría romana de la última mitad del siglo I a.C. Si bien BGU 4, 1132 no lleva ninguna marca distintiva sobre la identidad judía de las personas involucradas en el contrato, su conexión con BGU 4, 1151 ha permitido identificar a Teodoro y Alejandro con integrantes de la comunidad

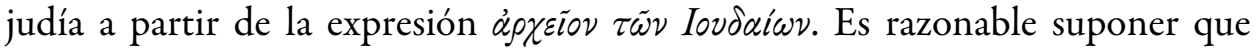
esta oficina judía disfrutó de algún tipo de reconocimiento oficial para otorgar validez al testamento de Teodoro, aunque no sabemos lo suficiente para llegar a una conclusión sobre su alcance o grado de autonomía jurídica, como tampoco sobre la relación de los judíos con la ley helenística. Sin embargo, BGU 4, 1132 ofrece datos significativos para lograr una aproximación a esta cuestión. De

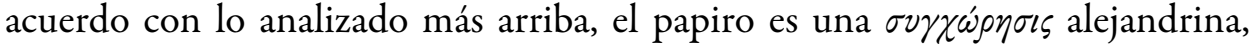
escrita en griego, autorizado por un órgano judicial no judío y acorde con los requisitos y las formas de la ley general prevalente en la ciudad. A partir de esta información, Tcherikover y Fucks (I, 1957, p. 32) proponen al menos dos

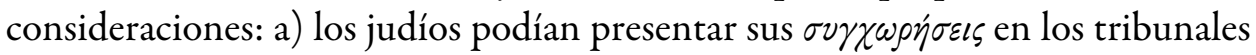

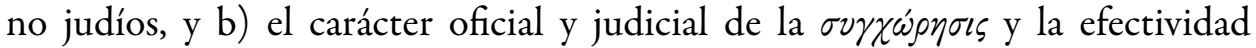
resultante asociada con este documento era sumamente útil para los judíos. Pese a que no se puede generalizar desde casos particulares, BGU 4, 1132 confirma las conclusiones de los editores. Aun cuando el papiro conviene cláusulas vinculadas con un préstamo que implica a la población judía, es un documento regular y

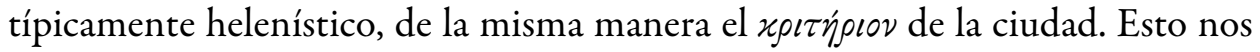
enfrenta a la probabilidad de que los judíos helenizados de las primeras décadas de Alejandría romana vivieran jurídicamente sujetos a los principios de la ley helenística común, y así lo demuestra BGU 4, 1132. Este papiro, junto con el resto de la documentación descubierta en la necrópolis de Abu Sir al-Malaq y procedente del archivo de Alejandría, es un texto con gran resonancia en los estudios históricos. Pese a que las lagunas del papiro y la incertidumbre acerca del contenido de la quinta $\sigma v \gamma \chi \omega ́ \rho \eta \sigma \iota \varsigma$ no favorecen la confirmación de los datos completos del documento, la traducción al castellano del texto allí conservado, y las notas sobre las restauraciones de los editores del papiro, ayuda a presumir al menos cuáles fueron las características de los contratos de préstamos contraídos por judíos de Alejandría y los órganos judiciales frecuentados por los miembros de esa comunidad. Esta es la causa por la que no se puede descartar el valor histórico de BGU 4, 1132. El contenido de la legislación helenística presente en este papiro, posiblemente referida al caso de judíos en Alejandría, da a conocer el grado de influencia de la ley helenística en la historia de los judíos en el temprano período romano de Egipto.

\section{Ediciones y traducciones}

Schubart, W. (1912). No 1132. En Aegyptische Urkunden aus den Koeniglichen Museen zu Berlin. Herausgegeben von der Griechische Urkunden, Vierter Band (pp. 240-242). Berlin: Weidmannsche Buchhandlung. = BGU 
Tcherikover, V. A. y Fuks, A. (1957-1960). Corpus Papyrorum Judaicarum (vol. I-II). Cambridge-Massachusetts: Harvard University Press. = CPJ

\section{Bibliografía citada}

Allam, S. (1984). Zum Aufkommen der notariellen Urkunde (Syngraphe und Synchoresis) im griechisch-römischen Ägypten. Studien zur Altägyptischen Kultur, 11, 175-181.

Arazy, A. (1977). The Appellations of the Jews (Ioudaios, Hebraios, Israel) in the Literature from Alexander to Justinian: From Alexander to Constantine (332 B.C.-312 A.D.). New York University.

Bowman, A. K. y Rathbone, D. W. (1992). Cities and Administration in Roman Egypt. The Journal of Roman Studies, 82, 107-127.

Calderini, A. (1935). Dizionario dei nomi geografici e topografici dell'Egitto greco-romano. Cairo: Societa\# reale di geografia D’Egitto.

Capponi, L. (2005). Augustan Egypt: The Creation of a Roman Province. London - New York: Routledge.

Díaz-Iglesias Llanos, L. (2016). Naref and Osiris Naref. A Study in Herakleopolitan Religious Traditions. Zeitschrift für ägyptische Sprache und Altertumskunde Beiheft 3. Walter de Gruyter.

Falivene, M. R. (1998). The Herakleopolite Nome. A Catalogue of the Toponyms with Introduction and Commentary. Atlanta: Scholars Press.

Fraser, P. M. (1972). Ptolemaic Alexandria (3 vols). New York: Oxford University Press.

Gambetti, S. (2009). The Alexandrian Riots of 38 C.E. and the Persecution of the Jews: A Historical Reconstruction. Leiden-Boston: Brill.

Goodenough, E. R. (1929). The jurisprudence of the Jewish courts in Egypt: Legal administration by the Jews under the early Roman Empire as described by Philo Judaeus. New Haven: Yale University Press / London: Oxford University Press.

Honigman, S. (2019). Ethnic Minority Groups. En K. Vandorpe (ed.), A companion to Greco-Roman and late antique Egypt (pp. 315-325). Hoboken, NJ: John Wiley \& Sons, Inc.

Ilan, T\#al et al. (2002-2008). Lexicon of Jewish names in late antiquity. Tu\#bingen: Mohr Siebeck.

Kasher, A. (1985). The Jews in Hellenistic and Roman Egypt: the struggle for equal rights. Tu\# bingen: Mohr.

Kugler, R.A. (2007). A Loan for "Dorotheos the Jew" (P.Polit. Iud. 8): Rethinking Law and the Jews in Light of the Herakl. Papyri. Paper presented at the $X X V$ International Congress of Papyrology, Ann Arbor, Michigan, July 29-August 4, 2007

Lesquier, J. (1918). L'armée romaine d'Égypte d'Auguste à Dioclétien. Le Caire.

Lippert, S. (2016). Egyptian Law, Saite to Roman Periods. En Classical Studies, Egyptology, Greek and Roman Law. Oxford.

Martin, C. J. et al.(2014). Leases. En J. G. Keenan, J. G. Manning y U. YiftachFiranko, U. (eds.), Law and Legal Practice in Egypt from Alexander to the Arab Conquest. A Selection of Papyrological Sources in Translation, with Introductions and Commentary (pp. 339-400). Cambridge: Cambridge University Press.

Martin, V. (1932). Un document relatif à l'éphébie. Chronique d'Egypte, 7(13-14), 300-310. 
Mélèze Modrzejewski, J. (1961). Les Juifs et le droit hellénistique: divorce et égalité des époux (CPJud. 144). Iura, 12, 162-177.

Mélèze Modrzejewski, J. (1991). Les Juifs d'Égypte, de Ramsès II à Hadrien. Paris: Éditions Errance.

Mélèze Modrzejewski, J. (1996). Jewish Law and Hellenistic Legal Practice in the Light of Greek Papyri from Egypt. En N. S. Hecht, B. S. Jackson, S. M. Passamaneck, D. Piattelli y A. Rabello (eds.), An introduction to the history and sources ofJewish law (pp. 75-99). New York: Oxford University Press.

Mélèze-Modrzejewski, J. (1975). Papyrologie et histoire des droits de l'antiquité. En École pratique des hautes études. 4e Section, Sciences historiques et philologiques. Annuaire 1974-1975 (pp. 325-341). Paris.

Mitteis, L. (1912). Grundzüge und Chrestomathie der Papyruskunde (con Ulrich Wilcken). Leipzig.

Parker, R. A. (1971). The Calendars and Chronology. En J. Harris (ed.), The Legacy of Egypt (pp. 13-26). London: Oxford University Press.

Riggs, Ch. (2005). The Beautiful Burial in Roman Egypt: Art, Identity, and Funerary Religion. Oxford: Oxford University Press.

Rubinstein, L. (2010). Praxis: the enforcement of penalties in the late classical and early Hellenistic period. En Symposion 2009. Vorträge zur griechischen und hellenistischen Rechtsgeschichte (Seggau, 25. 30. August 2009) (Akten der Gesellschaft für griechische und hellenistische Rechtsgeschichte 21) (ed. G. Thür) (pp. 193-213). Vienna: Verlag der österreichischen Akademie der Wissenschaften.

Runia, D. (1995). Philo and the Church Fathers. A Collection of Papers. Vigiliae Christianae, Supplements 32. Leiden - New York - Köln: Brill.

Rupprecht, H. - A. (1967). Untersuchungen zum Darlehen im Recht der graeco\# aegyptischen Papyri der Ptolemäerzeit (Münchener Beiträge zur Papyrusforschung und antiken Rechtsgeschichte 51). Munich: Beck.

Salmenkivi, E. (1997). Der Wert des archäologischen Kontextes für die Deutung der Urkunden-die Berliner Kartonage. En B. Kramer et al. (ed.), Akten des 21. Internationalen Papyrologenkongresses, Berlin, 13.-19.8. 1995 (Stuttgart, Leipzig: B.G. Teubner [ArchPF Beiheft 3 Band 2]). (pp. 1083-1087).

Salmenkivi, E. (2002). Cartonnage Papyri in Context: New Ptolemaic Documents From Abu Sir al-Malaq. Commentationes Humanarum 119. Helsinki: Societas Scientaiarum Fennica.

Sarischouli, P. (2000). Spätptolemäische Urkunden aus dem Herakleopolites. Ägyptische Urkunden aus den Staatlichen Museen Berlin. Griechische Urkunden 18.1. Bd. Staatliche Museen zu Berlin--Preussischer Kulturbesitz: [Ägyptisches Museum und Papyrussammmlung].

Schnebel, M., Otto, W. G. A. y Pluhatsch, F. (1925). Die Landwirtschaft im hellenistischen Ägypten. München: Beck.

Schubart, W. (1913). Alexandrinische Urkunden aus der Zeit des Augustus. Archiv für Papyrusforschung und verwandte Gebiete, 5, 35-131.

Schwartz, S. (2017). Law in Jewish Society in the Second Temple Period. En Ch. E. Hayes (ed.), Cambridge companion to Judaism and law (pp. 48-75). New York: Cambridge University Press.

Schwarz, A. B. (1911). Hypothek und hypallagma; beitrag zum pfand- und vollstreckungrecht der griechischen papyri. Leipzig, Berlin: B. G. Teubner. 
Seidl, E. (1962). Ptolema\#tische Rechtsgeschichte (2a ed.). Ägyptologische Forschungen 22. Glückstadt, New York: J.J. Augustin.

Seidl, E. y Müller, L. (1973). Rechtsgeschichte Agyptens als romischer Provinz: die Behauptung des ägyptischen Rechts neben dem römischen. Sankt Augustin: $\mathrm{H}$. Richarz.

Taubenschlag, R. (1955). The Law of Greco-Roman Egypt in the Light of the Papyri. 332 B.C.-640 A.D. (2a ed.). Warszawa: Panstwowe Wydawnictwo Naukowe.

Tomson, P. J. (1986). The Names Israel and Jew in Ancient Judaism and in the New Testament. Journal Bijdragen International Journal for Philosophy and Theology, 47, 266-289.

Williams, M. H. (2013).Jews in a Graeco-Roman Environment Juden in einer griechischrömischen Umgebung. Wissenschaftliche Untersuchungen zum Neuen Testament 312. Tübingen: Mohr Siebeck.

Wolff, H. J. (1941). The praxis - provision in papyrus contracts. Transactions of the American Philological Association, 72, 418-438.

Wolff, H. J. (1970). Das Justizwesen der Ptolemäer (2a ed.). Münchener Beiträge zur Papyrusforschung und antiken Rechtsgeschichte 44. München: C.H. Beck'sche Verlagsbuchhandlung.

Wolff, H. J. (1984). "Droit et justice dans le monde hellénistique au IIIe siècle avant notre ère. Expérience lagide”. Mnêmê G. A. Petropoulou, Athens, I, 53-77.

Wolff, H.-J. (1960). Plurality of Laws in Ptole maic Egypt. Revue Internationale des Droits de l'Antiquité, 3, 191-223.

Yiftach, U. y Vandorpe. K. (2019). Immigration, Globalization, and the Impact on Private Law. The Case of Legal Documents. En K. Vandorpe (ed.), A companion to Greco-Roman and late antique Egypt (pp. 179-198). Hoboken, NJ: John Wiley $\&$ Sons, Inc.

\section{Léxicos}

Rodríguez Adrados, F. (dir.) (DGE) (1980-2009). Diccionario Griego-Español (7 vols). Madrid: Instituto de Filología.

Liddell, H., Scott, R. y Jones, H. (LSJ) (1940). A Greek-English Lexicon. Oxford: Clarendon Press.

Yarza, F. (1945). Diccionario griego-español. Barcelona: Sopena.

\section{Notas}

1 Los ocho documentos están fechados hacia principios del Imperio de Augusto, específicamente entre los años 6 y 26 del principado. Fueron hallados por el arqueólogo Otto Rubensohn (1867-1964), designado por la Berliner Papyrus-kommission para dirigir la expedición destinada a las excavaciones de la necrópolis de Abu Sir al-Malaq, ubicada geográficamente en el sitio de un asentamiento en el nomo de Herakleópolis, cuyo antiguo nombre fue posiblemente Bousiris. Durante estas excavaciones se encontraron al menos dos grupos de documentación compuestos por papiros administrativos y literarios escritos en lengua griega y demótica, procedentes originalmente de los archivos de Herakleopolites, Arsinoites y Alejandría, y datados hacia el fin del período ptolemaico y principios de la era de Augusto. Algunos de estos papiros han sido publicados por Berliner Griechischen Urkunden (BGU), Berliner Kassikertext (BKT), o investigaciones independientes. Cf. Tcherikover y Fuks (II, 1960, p. 1); Falivene (1998); Sarischouli (2000); Salmenkivi (2002; cf. también 1997). 
Sobre la ubicación del sitio arqueológico de Abu Sir al-Malaq, cf. Díaz-Iglesias Llanos (2016, p. 5); también Riggs (2005, p. 148).

2 Esta conclusión está basada en las alusiones geográficas y topográficas dadas a conocer por los papiros (cf. Tcherikover y Fuks, II, 1960, p. 1; Schubart, 1913, p. 37 ss.), que se unen a la aparición de soldados que sirven en la 22a legión asentada en la capital (cf. Lesquier, 1918, p. 388), la evidencia del papiro BGU 4, 1140 (= CPJ 2, 151, 1. 4, año 5/4 a.C.), donde la palabra griega $\dot{\varepsilon} v \tau \alpha \tilde{v} \vartheta \alpha$ ha sido asociada directamente con la ciudad portuaria y a la mención de instituciones específicamente alejandrinas,

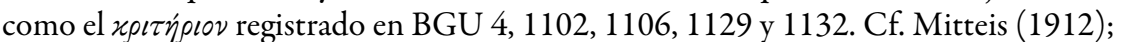
Tcherikover y Fuks (II, 1960, p. 1); Wolff (1984); Mélèze Modrzejewski (1991). El más reciente estudio sobre los judíos en Alejandría pertenece a Honigman (2019, pp. 320-321).

3 Habrían sido conservados en la oficina del tribunal (cf. Yiftach y Vandorpe, 2019, p. 182), en la oficina del asesor legal (cf. Seidl y Muller, 1973, p. 67), o en la oficina del escriba del procurador (cf. Schubart, 1913, p. 45) de la ciudad portuaria.

4 Para un caso similar, cf. BGU 4, 1155; Mitteis, Chr. 67; Schubart, Arch. v. 63, n. 1 (parte); también BL 2, 2, 24; CPJ 2, 148.

5 Las variantes léxicas de las ediciones de Schubart y Tcherikover y Fuks han sido aclaradas en las notas que acompañan el original griego.

6 El texto griego editado por Schubart (1912, pp. 240-242) y Tcherikover y Fuks (II, 1960, pp. 5-8) contiene los siguientes símbolos: 1) los paréntesis () indican la resolución de un símbolo o abreviatura, 2) los corchetes [] señalan una laguna, 3) los corchetes angulares <>marcan una omisión errónea en el original, 4) las llaves \{\} precisan una letra o letras superfluas, y 5) los corchetes dobles [[ ]] aclaran una eliminación.

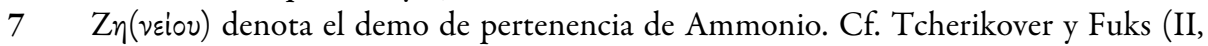
1960, p. 8); también Schubart (1913, p. 82); Martin (1932, p. 301).

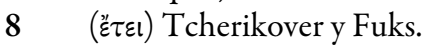

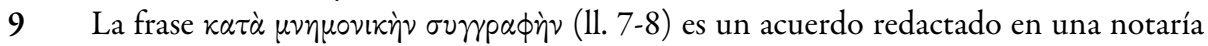
( $\mu \nu \eta \mu о \nu \varepsilon i ̃ \nu)$. Cf. Schubart $(1913$, p. 77$)$.

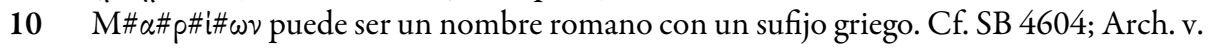
175 n. 26; SB 4374, 7354; Tcherikover y Fuks (II, 1960, p. 8).

11 Mediante la frase $\kappa \alpha \tau \grave{\alpha} \delta ı \gamma p \alpha \phi \grave{\eta}(\nu) \delta i \dot{\alpha} \tau \tilde{\eta}(\varsigma)(\ldots) \tau p \alpha \pi\left(\dot{\varepsilon} \zeta_{\eta} \zeta\right)$ se hace referencia a un documento autenticado por un banco. Cf. Tcherikover y Fuks (II, 1960, p. 8).

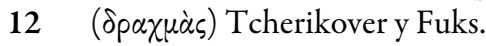

13 Schubart (1912, p. 240) considera que también se puede leer $\pi p \circ s-\beta \varepsilon \beta \alpha$ เoṽ $\sigma \alpha$ l en lugar de $\pi \rho \varsigma-\beta \varepsilon \beta \lambda \tilde{\eta} \sigma \theta \alpha$. Sin embargo recomienda $\pi \rho \varsigma-\beta \varepsilon \beta \lambda \tilde{\eta} \sigma \theta \alpha \iota$ por su relación con $\pi \rho \circ \sigma \beta о \lambda \eta \dot{\nu}(1.17)$.

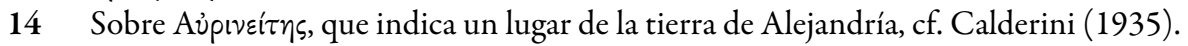

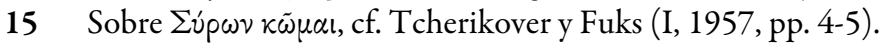

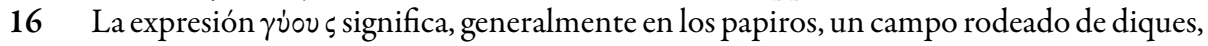
también una parcela (cf. P.Lips. 1, 106, 1. 16). Al parecer, $A \lambda \varepsilon \xi \alpha \nu \delta(\rho \dot{\varepsilon} \omega \nu) \chi \omega \dot{\omega} \rho \alpha(\varsigma)$

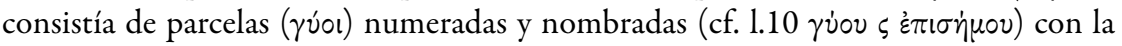

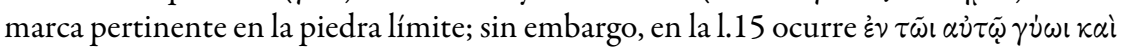
$\dot{\varepsilon} \pi(เ \sigma \dot{\eta} \mu \omega)$. Cf. Tcherikover y Fuks (II, 1960, p. 8).

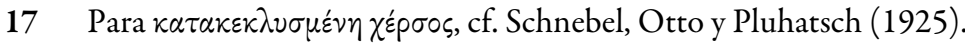

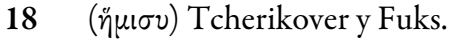

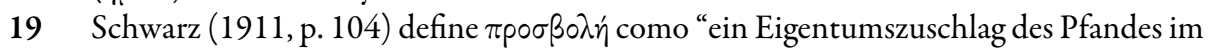
Vollstreckungsverfahren”. Cf. Taubenschlag (1955, pp. 276, 527, 533, 535, nota 21).

20 Debido a que la forma del artículo femenino singular $\tau \tilde{\eta} \varsigma$ no genera dudas en su lectura, Schubart (1912, p. 241) transcribe Api $\tau \tau$ เov y le adjudica valor femenino.

$21 \tau[\alpha] / \tau[\tilde{\omega} \nu]$ Schubart.

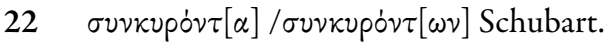

23 हे $\gamma \alpha \sigma \tau \eta p i[\alpha] /$ हैp $\gamma \alpha \sigma \tau \eta p i[\omega \nu]$ Schubart.

$24 \psi i \lambda[$ ov $] / \psi i \lambda[\tilde{\omega} \nu]$ Schubart.

$25 \tau \dot{0} \pi[0 \nu \varsigma] / \tau \dot{o} \pi[\omega \nu]$ Schubart. Ammonios se ha apoderado de la tierra bajo cultivo



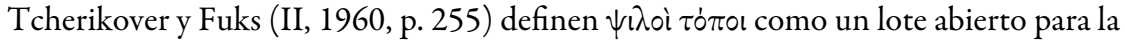
construcción de viviendas. 
26 oiko $\pi \dot{\varepsilon} \delta[\alpha] /$ oiko $\pi \dot{\varepsilon} \delta[\omega \nu]$ Schubart.

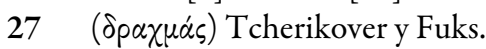

$28(\delta \rho \alpha \chi \mu \tilde{\omega} \nu)$ Tcherikover y Fuks.

$29 \Pi \alpha \rho[\alpha \kappa \varepsilon] \chi \omega \dot{\omega} p \eta[\mu] \varepsilon \nu / \Pi \alpha \rho[\varepsilon] \chi \omega ́ p \eta[\sigma] \varepsilon \nu$ Schubart.

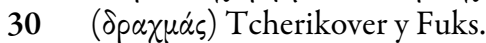

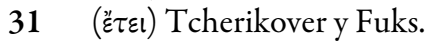

$32(\delta \rho \alpha \chi \mu \tilde{\omega} \nu)$ Tcherikover y Fuks.

33 Inserción de nombre propuesta por Schubart (1912, p. 241).

34 Para Schubart (1912, p. 241), la partícula $\tau \varepsilon$ se encuentra detrás de una serie de palabras

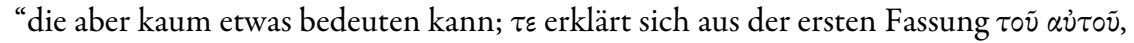

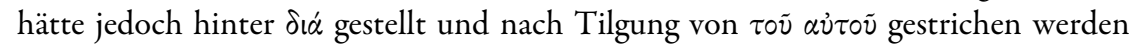
müssen".

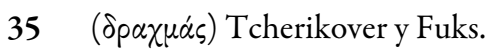

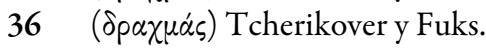

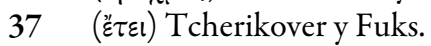

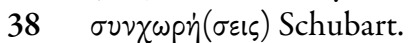

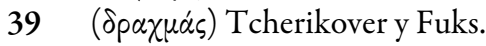

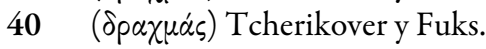

$41 S i \mu[\eta \nu \tilde{\omega} v$ es correcto, requiere un número de meses. Cf. Schubart (1912, p. 242).

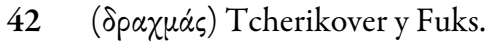

43 Lagunas en el papiro.

44 Schubart (1912, p. 242) sugiere $\tau \dot{\alpha} \varsigma$ o $\tau \tilde{\eta} \varsigma$ o $\tau \alpha i \check{\varsigma}$.

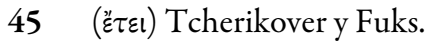

46 Según Schubart (1912, p. 242), el papiro presenta rastros menores de varias líneas hasta el borde del papiro. Cf. Tcherikover y Fuks (II, 1960, p. 7).

47 Cf. Schubart (1912, p. 242).

48 La traducción del texto griego ha sido realizada a partir de las ediciones de Schubart (1912) y Tcherikover y Fuks (II, 1960). Solo hemos agregado los siguientes símbolos: 1) los corchetes [] suman palabras que, aunque ausentes en el texto griego, precisan el sentido de algunas expresiones confusas en el documento, y 2) los paréntesis () indican especificaciones contextuales. Por su parte, algunas palabras del papiro han sido trasliteradas (Protárchos, 1. 1; práktores, 1. 8, 17, Fr.; chóra, 1. 10; prosbolé, 1. 17, 23, Fr.) debido a la ausencia de un significado castellano que denote el sentido completo del término en cuestión.

49 “Tot” $(\Theta \omega \tilde{v} \theta)$, también “Thoth”, es el mes egipcio correspondiente a la franja temporal que se extiende desde el 29 de agosto hasta el 27 de septiembre. Sobre el calendario egipcio de la época de Augusto, cf. Harris (1971, pp. 13-26).

50 Según Taubenschlag (1955, pp. 677-678), en Egipto ptolemaico existieron

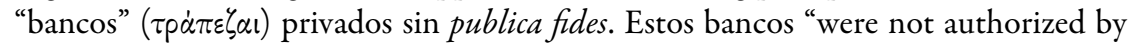
the State"; eran bancos sin licencia que practicaban servicios sin estar debidamente calificados y aparentemente eran conocidos por los nombres de sus dueños. Cf. P. Oxy. 14, 1639, 1l. 5 y 30 (año 73 o 44 a.C.); P. Lond. 3, 890, 1. 12, p. 168 (año 6 a.C.); Amh. 68, 1.20 (siglo I a.C.). En el período romano todavía existían estos bancos de particulares, como lo muestra BGU 4, 1132. Cf. Yiftach y Vandorpe (2019, p. 180).


A $\beta$ p $\tau \dot{\alpha}$ vov) indica un región, zona o área geográfica del Bajo Egipto, perteneciente a la administración de la chóra de Alejandría.

52 La "arura" (äpovp $\alpha$ ) significa literalmente "tierra arable", "tierra cultivable" o "campo de labor”. Cf. Homero, Iliada 6, 195; 11, 68; 18, 544; Aristóteles, Meteorología 341b26. Aunque en Egipto helenístico adquiere el sentido de medida de superficie equivalente a $2.623 \mathrm{~m}^{2}$. Cf. Heródoto 2, 168; Hecateo de Abdera 21, 195; OGI 90, 30; también P.Lugd.Bat.20, 6, 7; 20, 60, 4, 9 (siglo III a.C.); P.Oxy.45, 12 (siglo I d.C.); P.Ryl.143, 17 (siglo I d.C.).

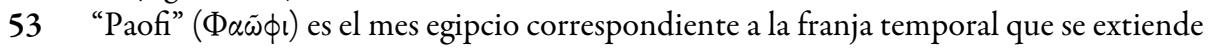
desde el 28 de septiembre hasta el 27 de octubre.

54 "Atir" (AӨúp) es el mes egipcio que abarca desde el 28 de octubre hasta el 27 de noviembre. Cf. I.Herm.Magn. 46, 7 (siglo II d.C.); I.Ph. 190, 4 (siglo V d.C.). 
55 "Pauni" (П $\alpha \tilde{\nu} v \imath$ ), también "Payni”, es el mes egipcio correspondiente a la franja temporal que se extiende desde el 26 de mayo hasta el 24 junio.

56 El documento apunta que Teodoro y Alejandro son hijos "de Nicodemo

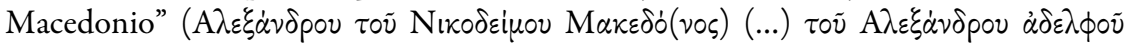


que indicaría la pertenencia de los hermanos judíos a una unidad nacional

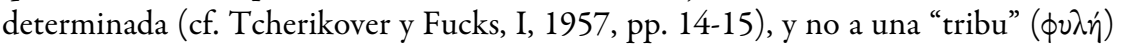
como propone Josefo. Cf. Contra Apión 2, 36; también La guerra de los judíos 2, 487-489; Antigüedades judias 12, 8.

57 Sobre los nombres usados por los judíos en el período ptolemaico y romano, cf. Tcherikover y Fuks (I, 1957, pp. XVII-XIX); Tal Ilan et al. (2002-2008).

58 La forma $k 0^{\lambda}$ se encuentra escrita más grande en el papiro. Schubart (1912: 276) sugiere que podría pertenecer a la mano de otro copista.

59 El texto griego fue editado primeramente por Schubart (1912: 276-277 = BGU 4, 1151) y reeditado por Tcherikover y Fuks (II, 1960: 8-10 = CPJ 2, 143). Nuestra traducción es directa del griego y sigue las ediciones de estos autores. Para los símbolos usados en el texto griego y en la traducción, cf. supra notas 6 y 48.

60 Una judía egipcia llamada Dionisia también aparece en una inscripción (CIJ II, 1532), ubicada en el inicio del período romano.

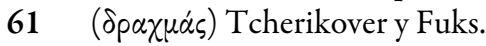

$62(\delta \rho \alpha \chi \mu \tilde{\omega} \nu)$ Tcherikover y Fuks.

63 Según Schubart (1912, p. 276), o $\mu \varepsilon \tau \eta \lambda \lambda \alpha \chi$ es “sehr undeutlich”, especialmente al final, donde podría reconstruirse $\mu \varepsilon \tau \eta \lambda \lambda \alpha \chi(\grave{\omega} \varsigma)$ con la terminación " $\varepsilon ı \varsigma(=\varepsilon \nu \alpha l$ ? )", que solo puede presuponerse a partir de la conexión con las líneas anterior y siguiente.

64 Schubart (1912, p. 276) supone que el final parece haber sido tachado.


es clara, $\delta$ o $\alpha$ aparecen confusas, sin embargo el final no presenta dudas.

$66(\delta p \alpha \chi \mu \tilde{\omega} \nu)$ Tcherikover y Fuks.

67 La parte media de la l. 10 es incierta. Schubart (1912, p. 276) sugiere “ $\alpha \varsigma$ ó $\phi \varepsilon i(\lambda \varepsilon l)$ ?”.

68 El número de meses está de acuerdo con la 1.24. Cf. Schubart (1912, p. 276).

69 (हैं०ข५) Tcherikover y Fuks.

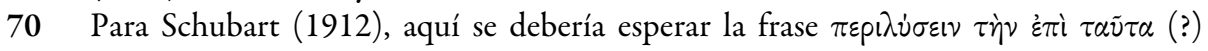

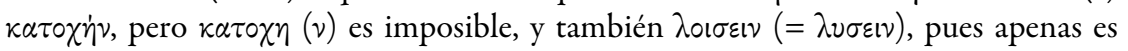
compatible con lo que se ha conservado.

71 "Farmuti" $\left(\Phi \alpha \rho \mu\left(\circ \tilde{u} \theta_{\imath}\right)\right)$, también "Pharmuthi”, es el mes egipcio correspondiente a la franja temporal que se extiende desde el 27 de marzo hasta el 25 de abril.

72 Sobre el término Iovdaĩos, cf. Arazy (1977); Tomson (1986); Runia (1995); Williams (2013).

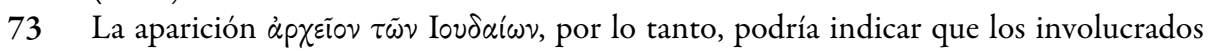
en el papiro son judíos. Así lo sugieren Bowman y Rathbone (1992, p. 117); Kugler (2007); Gambetti (2009, p. 52, nota 115). Cf. P.Polit. Iud. 8 (año 133 a.C.).

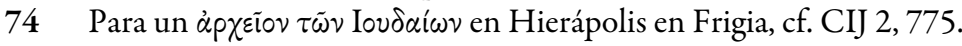

75 Posiblemente adoptado de la ley griega antigua. Cf. Taubenschlag (1955, p. 190).

76 Cf. SB 6997 (siglo III a.C.).

77 Schubart (1912, p. 276) restaura $\dot{\alpha} \pi \circ \delta \hat{\delta} \delta \omega \sigma$, aunque también sugiere $\dot{\alpha} \pi \circ \delta \tilde{\omega}$. Cf. Tcherikover y Fuks (I, 1957, p. 10), quienes también proponen esta enmienda.

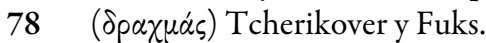

79 Schubart (1912, p. 277) estima que los datos de la 1.14 seguramente fueron proporcionados por el escriba. Schubart también sugiere la siguiente lectura: $\tau \dot{\alpha} \varsigma \tau \sigma \tilde{v}$

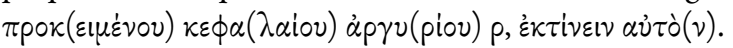

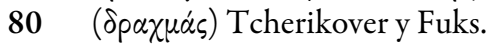

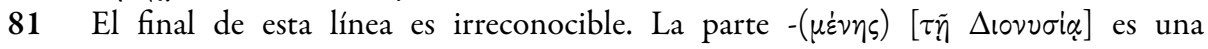
reconstrucción de Schubart (1912, p. 277).



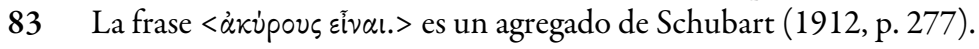

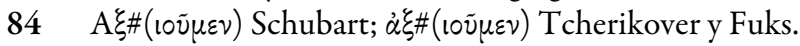

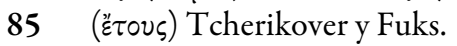

$86(\delta \rho \alpha \chi \mu \tilde{\omega} \nu)$ Tcherikover y Fuks. 


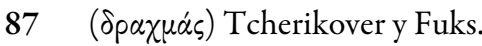

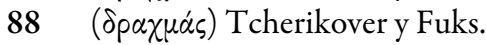

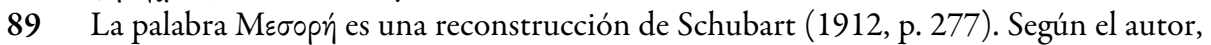
esta enmienda es confirmada por la 1. 10. "Mesore" es el mes egipcio correspondiente a la franja temporal que se extiende desde el 25 de julio hasta el 23 agosto.

90 El número $\zeta$ no es claro en el documento. Cf. Schubart (1912, p. 277).

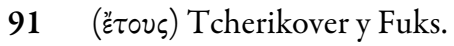

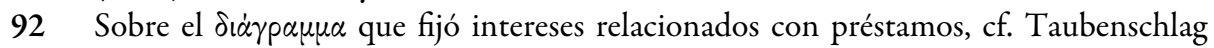
(1955, p. 343).

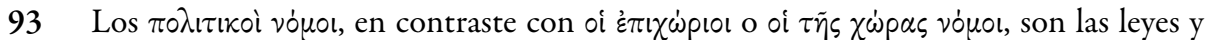
reglamentos griegos. Fueron recolectados de los vó $\mu \circ$ y $\psi \eta \phi i \sigma \mu \alpha \tau \alpha$ de varias ciudades griegas y confirmadas por el rey ptolemaico como un código regular de derecho cívico para la población griega de Egipto. Cf. Taubenschlaug (1955, pp. 9-14); Mélèze Modrzejewski (1975, pp. 325-341).

94 Sobre el $\delta \dot{\alpha} \gamma p \alpha \mu \mu \alpha$ en general, cf. Wolff (1960, p. 206, nota 40).

95 Según Wolff (1960, p. 206), sostiene que las fuentes usualmente anotan el neutro

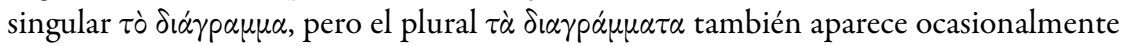
(cf. BGU 4, 1213; Gurob. 2, 1, 43 ss.; Gurob. 7; Ent. 14, 15, 16; Sammelb. 1, 5675, 1. 10). Cf. Wolff (1960, p. 206).

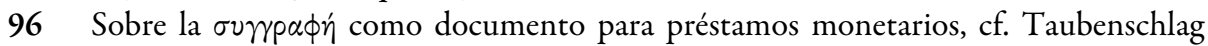
(1955, p. 294, especialmente p. 341); Allam (1984); más recientemente Yiftach y Vandorpe (2019).

97 También hay escritos demóticos de este tipo de documento. Cf. Seidl (1962); Lippert (2016).

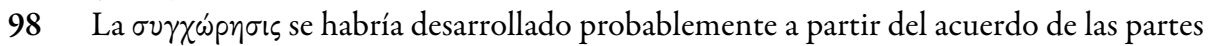

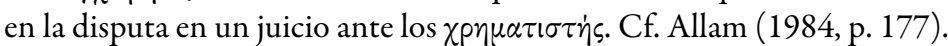

99 A partir del siglo I d.C., la función de recibir las $\sigma \nu \gamma \chi \omega p \eta \dot{\sigma \varepsilon \mid \varsigma, ~ i n c o r p o r a r l a s ~ e n ~ e l ~ r e g i s t r o ~}$ oficial y emitir una escritura con los detalles del acuerdo habría sido transferida a una

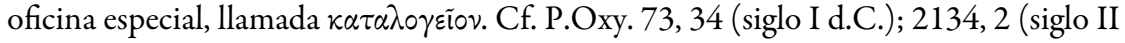
d.C.).

100 Los ocho documentos alejandrinos hallados en la necrópolis de Abu Sir al-Malaq indican que la actividad del Protárchos fue continua entre los años 16 y 26 de Augusto.

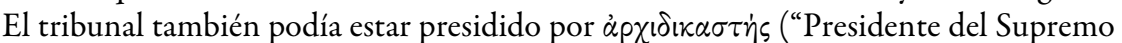

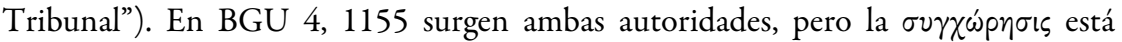
encabezada por la figura del Protárchos. Cf. 1l. 1-7; Schubart (1913); Tcherikover y Fuks (II, 1960, p. 4). Este título encabeza la mayoría de los documentos alejandrino de Abusir el-Meleq (BGU 4, 1151, 1. 2; 1102, 1. 2; 1129, 1. 2; 1106, 1. 1; 1155, 1. 2; 1134, 1. 1), incluido BGU 4, 1132, que señala la actividad del Protárchos a partir del año 14 a.C. Solo BGU 4, 1153, I no conserva el inicio del contrato. Cf. Martin et al. (2014, p. 377).

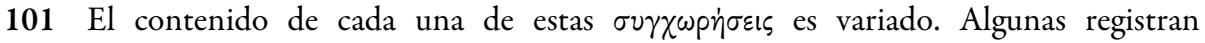
transacciones relacionadas con acuerdos de divorcio (BGU 4, 1102), contrataciones de nodrizas $(4,1106)$ y anulaciones de estos contratos $(4,1153 \mathrm{I})$. Otras $\sigma \nu \gamma \chi \omega \rho \eta \dot{\sigma \varepsilon ı \varsigma ~ s o n ~}$ escrituras directamente ligadas con legados concedidos por una de las partes a través de un testamento asentado en una oficina notarial $(4,1151)$, devolución de dinero y transferencias de tierras $(4,1129)$, y préstamos y reembolsos $(4,1132)$.

102 El término es usual en los documentos del siglo I d.C. en adelante. Cf. P.Cair.Preis. 43, 10 (siglo I d.C.); P.Amh. 2, 111, 16 (siglo II d.C.); BGU 578, 21 (siglo II d.C.); 1657, 6 (siglo III d.C.).

103 Schubart (1913, p. 58, nota 3) sostiene que no existe diferencia entre kpıฑ่pıov y $\delta$ $к \alpha \sigma \tau \dot{p}$ iov. De acuerdo con su interpretación, los documentos más antiguos dicen

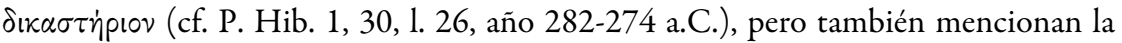
palabra kpı ท́рı⿻v (P. Hib.1, 29, 1. 5, año 265 a.C.).

104 En este papiro también aparece el $\delta 1 \alpha<1>\tau \eta \tau \eta \dot{s}$ (col. II, 1. 41-42) como parte de

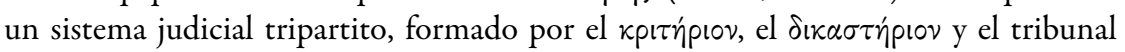

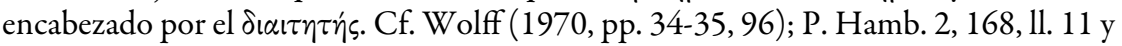
ss, y 18 (ca. años 275 y 226 a.C.); también Taubenschlag (1955, p. 484).

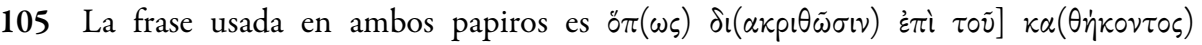






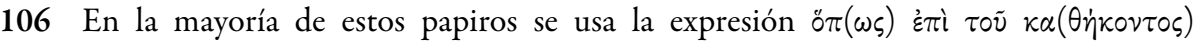
$\delta_{l}(\kappa \alpha \sigma \tau \eta p i o v) \delta_{l}(\alpha \kappa p l \theta \tilde{\omega} \sigma \iota v)$ hacia el final del texto. Sobre esta construcción, cf. Wolff (1970, p. 97, nota 2).

107 Cf. Wolff (1970, p. 97, nota 2).

108 Cf. P.Hamb. 2, 168a, 1. 2; 168b, 1.8 (ca. años 275 y 226 a.C.); P.Hib. 1, 29, 1. 5 (año 265 a.C.); P.Bingen 34, 1.5 (ca. años 225 y 176 a.C.); SB 14, 12163, 11.15 y 22 (ca. años 175 y 126 a.C.); etc.

109 En distintos documentos de los siglos III, II y I a.C. encontramos activo el кpı Cf. SB 14, 12163 (siglo II a.C.); P.Polit. Iud. 12 (año 135 a.C.); también BGU 3, 1001, 2; 4, 1059, 1; 4, 1099, 1; 4, 1159; entre otros. Este tribunal surge junto a otros dos

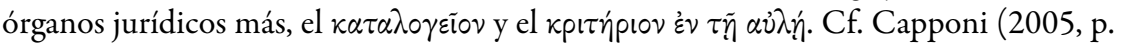
39). Podemos suponer que el funcionamiento de este grupo de tribunales habría estado confinado al ámbito de la ley privada (cf. Fraser 1972, pp. 113-114), encargado de la elaboración y tratamiento de las $\sigma \nu \gamma \chi \omega p \eta ́ \sigma \varepsilon เ \varsigma$ y escritos similares, y cada uno podría haber servido a los habitantes de un barrio determinado. En el archivo de los papiros

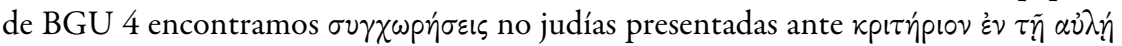
(años 18 y 15 a.C.), mientras que otras $\sigma \nu \gamma \chi \omega p \eta ́ \sigma \varepsilon ı$ fueron presentadas ante el кpı $\tau \dot{\rho}$ เov (años 14 y 5 a.C.). Cf. Schubart (1913); Yiftach y Vandorpe (2019, p. 182).

110 Los judíos también tenían sus propios tribunales autónomos, cuya existencia está implícita en un pasaje de Estrabón (cf. Josefo, Antigüedades judias 14, 117) y atestiguado en la literatura rabínica (cf. t.Ketubot 3, 1 (= Peá 4, 8); b.Ketubot 25a; y.Ketubot 2, 26d; Peá 4, 6).

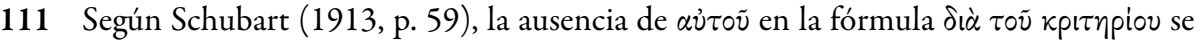

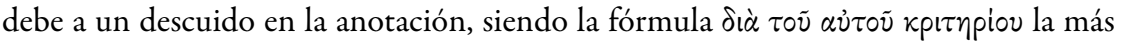
habitual en la mayoría de los documentos.

112 Sobre los judíos de la chóra egipcia, cf. Kasher (1985, pp. 106-167).

113 Cf. BGU 4, 1129.

114 Cf. P. Tebt. 814; también P. Tebt. 5, 231-235; 814, 29-35.

115 La propiedad inmueble del deudor se convirtió en la garantía de cobro y el deudor fue constantemente responsable de garantizar la cobertura del monto total de la deuda contraída para evitar que el acreedor ejerciera su derecho a iniciar una acción judicial en su contra y solicitar la obligación de la indemnización.

116 El término técnico para esta operación es $\pi \alpha \rho \dot{\alpha} \delta \varepsilon ı \xi ı$. Cf. P. Meyer 1, 1. 5.

117 Cf. BGU 6, 1246 (siglo III a.C.). 